\title{
Sensitivity analyses of biodiesel thermo-physical properties under diesel engine conditions
}

\author{
Cheng, Xinwei; Ng, Hoon Kiat; Gan, Suyin; Ho, Jee Hou; Pang, Kar Mun
}

\author{
Published in: \\ Energy
}

Link to article, DOI:

10.1016/j.energy.2016.04.103

Publication date:

2016

Document Version

Peer reviewed version

Link back to DTU Orbit

Citation (APA):

Cheng, X., Ng, H. K., Gan, S., Ho, J. H., \& Pang, K. M. (2016). Sensitivity analyses of biodiesel thermo-physical properties under diesel engine conditions. Energy, 109, 341-352. https://doi.org/10.1016/j.energy.2016.04.103

\section{General rights}

Copyright and moral rights for the publications made accessible in the public portal are retained by the authors and/or other copyright owners and it is a condition of accessing publications that users recognise and abide by the legal requirements associated with these rights.

- Users may download and print one copy of any publication from the public portal for the purpose of private study or research.

- You may not further distribute the material or use it for any profit-making activity or commercial gain

- You may freely distribute the URL identifying the publication in the public portal 


\section{Sensitivity analyses of biodiesel thermo-physical properties under diesel engine}

\section{2 conditions}

3 Xinwei Cheng ${ }^{1}$, Hoon Kiat $\mathrm{Ng}^{1 *}$, Suyin $\mathrm{Gan}^{2}$, Jee Hou Ho ${ }^{1}, \mathrm{Kar}_{\text {Mun }} \mathrm{Pang}^{3}$

$4{ }^{1}$ Department of Mechanical, Materials and Manufacturing Engineering, The University of

5 Nottingham Malaysia Campus, Jalan Broga, 43500 Semenyih, Selangor Darul Ehsan,

$6 \quad$ Malaysia.

$7 \quad{ }^{2}$ Department of Chemical and Environmental Engineering, The University of Nottingham

8 Malaysia Campus, Jalan Broga, 43500 Semenyih, Selangor Darul Ehsan, Malaysia.

$9{ }^{3}$ Department of Mechanical Engineering, Technical University of Denmark, Nils Koppels 10 Allé, 2900 Kgs. Lynby, Denmark.

$11 *$ Corresponding author: Tel: +603 89248161; Fax: +603 89248017; Email-address: 12 hoonkiat.ng@nottingham.edu.my (H. K. Ng)

14 Abstract

15 This reported work investigates the sensitivities of spray and soot developments to the change 16 of thermo-physical properties for coconut and soybean methyl esters, using two-dimensional 17 computational fluid dynamics fuel spray modelling. The choice of test fuels made was due to 18 their contrasting saturation-unsaturation compositions. The sensitivity analyses for nonreacting and reacting sprays were carried out against a total of 12 thermo-physical properties, at an ambient temperature of $900 \mathrm{~K}$ and density of $22.8 \mathrm{~kg} / \mathrm{m}^{3}$. For the sensitivity analyses, all the thermo-physical properties were set as the baseline case and each property was individually replaced by that of diesel. The significance of individual thermo-physical property was determined based on the deviations found in predictions such as liquid penetration, ignition delay period and peak soot concentration when compared to those of 
25 baseline case. Among all the properties, latent heat of vaporisation produced the greatest 26 effect on the spray and soot developments under the tested conditions, as evidenced by a 27 longer liquid penetration of $35.0 \%$ and a reduced peak soot concentration of $22.8 \%$. Besides, 28 coupled effects among the thermo-physical properties were discovered. Meanwhile, the 29 effects of thermo-physical properties were also found to vary according to the addition of 30 unsaturation levels and combustion chemistries.

32 Keywords: biodiesel, CFD, spray, thermo-physical properties 
The rise of biodiesel as a reliable alternative fuel has stimulated extensive interest and research to further exploit this fuel for power generation in ground transportation sector. Therefore, numerous studies have been conducted either on experimental or numerical fronts to understand the combustion characteristics of biodiesel under engine environment. Many apparent benefits are reported when biodiesel is utilised in diesel engine, such as low levels of carbon monoxide [1], soot formation [1] and particulate matter emissions [2,3]. However, several drawbacks are also found when biodiesel is directly fuelled into diesel engine, without any modification to the engine. For example, the lower heating value of biodiesel as compared to that of diesel contributes to the increased fuel consumption and lower engine power output [1]. Furthermore, higher levels of nitrogen oxides emission [1,4] are also detected when biodiesel replaces diesel.

One main reason that contributes to the distinct combustion characteristics between diesel and biodiesel is the fuel compositions. The majority components contained within chemical structures of these two fuels are dissimilar as biodiesel contains additional oxygen atom and double bonds in comparisons to the pure hydrocarbons in diesel. As such, the thermo-physical properties of biodiesel, which are developed based on the fuel compositions, are distinguishable from those of diesel. Several experimental works have discovered that the spray characteristics of biodiesel are contributed by the fuel thermo-physical properties. For example, Genzale et al. [5] suggested that the higher values of liquid density and liquid viscosity of biodiesel contributed to longer liquid penetration length (LPL) than that of diesel. On the other hand, Nerva et al. [6] noticed that the higher mass flow rate for soybean methyl ester (SME) was due to the higher liquid density and liquid viscosity. Apart from these 
numerical modelling. For example, Kuti et al. [7] detected that the extended LPL of palm methyl ester (PME) as compared to that of diesel was caused by the higher boiling point of the biodiesel. Besides, Lee and Huh [8] also pointed out that the larger Sauter Mean Diameter (SMD) and slower mixing rate of SME are induced by the higher liquid viscosity and liquid surface tension of biodiesel as compared to those of diesel. These studies have thus proven the key role of thermo-physical properties in the development of spray.

As such, many studies have since been conducted to develop accurate thermophysical properties for biodiesel [9-14]. For example, several key thermo-physical properties for SME such as critical properties, liquid density and latent heat of vaporisation were evaluated by Yuan et al. [9] using different correlations found in the literature. In their reported work, Yuan et al. [9] observed that the evaluated thermo-physical properties was influenced by the unsaturation levels of biodiesel although the evaluated properties were not validated. Besides, precise estimations of boiling points for the fatty acid methyl ester (FAME) components and biodiesel mixtures are also emphasized because the boiling point values are further adopted into the calculations of other thermo-physical properties [15].

Despite the increasing awareness of the need to formulate more precise thermophysical properties, only a handful of works have been conducted to evaluate the effects of thermo-physical properties of biodiesel. Ra et al. [13] were one of the earliest groups who analysed the effects of thermo-physical properties of biodiesel. Based on their single drop and diesel engine simulations, they identified the importance of liquid density and vapour pressure on single drop vaporisation, retardation in injection timing, ignition delay (ID) period and in-cylinder peak pressure. Nevertheless, the possibility of coupled effects in diesel engine simulation was suggested by Ra et al. [13] because no distinct changes in combustion characteristics were observed when the individual thermo-physical property of SME was substituted. In another separate study by Mohamed Ismail et al. [14], an analysis on the 
sensitivities of thermo-physical properties specifically for PME was carried out based on the simulations of spray and diesel engine combustion. Mohamed Ismail et al. [14] concluded that liquid density, liquid surface tension, vapour diffusivity and vapour pressure were the most sensitive fuel properties. Besides, collective effects from all the thermo-physical properties were also identified because increased errors were detected in the predicted ID period and vaporised fuel mass when all the thermo-physical properties of PME were substituted by those of diesel. These works however did not focus on the sensitivities of the fuel spray development to the thermo-physical properties for biodiesel fuels which are derived from different feedstocks. Additionally, the analyses carried out by Ra et al. [13] and Mohamed Ismail et al. [14] did not consider the influence of individual fuel property on the soot development during quasi-steady period.

Based on these, this work aims to understand how do the thermo-physical properties affect the quasi-steady spray and soot while retaining similar numerical case settings and chemical kinetics throughout the analyses. Here, these issues are addressed by conducting sensitivity analyses under quasi-steady non-reacting spray and reacting spray conditions. The sensitivity analyses are performed with an open-source computational fluid dynamics (CFD) code, Open Field Operation and Manipulation (OpenFOAM) version 2.0.x for coconut methyl ester (CME) and SME, where both fuels represent low and high levels of unsaturation, respectively. The predicted spray and soot results for CME are compared against those of SME such that the significance of unsaturation levels can be identified. Besides, selected individual thermo-physical property is coupled together in order to determine the coupled effects among the thermo-physical properties for CME and SME, respectively. Furthermore, the influence of combustion chemistries on the thermo-physical properties is also assessed by comparing the predictions between the non-reacting and reacting sprays. For all the sensitivity analyses, the baseline case is defined as the case where all the thermo-physical 
properties are specified. In the non-reacting sensitivity analyses for individual and coupled thermo-physical properties, the identification of significant fuel properties is based on the deviations found in the predictions of LPL, vapour penetration length (VPL), SMD, radial mixture fraction and fuel evaporation ratio when compared to those of baseline case. Meanwhile, the predicted LPL, ID period, lift-off length (LOL) and soot volume fraction (SVF) in the reacting spray are the parameters used to appraise the effects of individual thermo-physical property. Here, the analysis on coupled properties is excluded because the coupled effect can be combined from the effect of individual thermo-physical property, as identified from the non-reacting spray analysis.

\section{Methodology of sensitivity analysis}

\subsection{Development of thermo-physical properties}

Two types of biodiesel fuels namely, CME and SME were selected here because of their contrasting saturation and unsaturation levels, as shown in Table 1. The thermo-physical properties for CME and SME, which were plotted against a temperature range of $280 \mathrm{~K}$ up to the critical temperature of each fuel as shown in Figure 1(a) to (1), were calculated based on the actual fuel compositions in Table 1. Similar methods of evaluation to those of Mohamed Ismail et al.'s work [14] as listed in Table 2 were employed here. Improvement was made to the evaluation of vapour diffusivity by taking into account of the binary interaction between fuel and air as proposed in the Lennard-Jones potential [16], instead of the binary interactions among FAME components considered by Mohamed Ismail et al. [14]. The newly evaluated vapour diffusivities for CME and SME in Figure 1(h) correspond similarly to those published by Ra et al. [13], for which the vapour diffusivities of biodiesel are higher than those of diesel. On the other hand, the thermo-physical properties for diesel were calculated using the 
FAMEs

\section{Fuel types}

CME wt. (\%)
SME wt. (\%)

\begin{tabular}{lll}
\hline Saturated & & \\
\hline Methyl laurate $\left(\mathrm{C}_{13} \mathrm{H}_{26} \mathrm{O}_{2}\right)$ & 47.0 & - \\
Methyl myristate $\left(\mathrm{C}_{15} \mathrm{H}_{30} \mathrm{O}_{2}\right)$ & 19.0 & 8.0 \\
Methyl palmitate $\left(\mathrm{C}_{17} \mathrm{H}_{34} \mathrm{O}_{2}\right)$ & 10.0 & 4.0 \\
Methyl stearate $\left(\mathrm{C}_{19} \mathrm{H}_{38} \mathrm{O}_{2}\right)$ & 3.0 & \\
\hline Unsaturated & & 25.0 \\
\hline Methyl oleate $\left(\mathrm{C}_{19} \mathrm{H}_{36} \mathrm{O}_{2}\right)$ & 7.0 & 55.0 \\
Methyl linoleate $\left(\mathrm{C}_{19} \mathrm{H}_{34} \mathrm{O}_{2}\right)$ & 2.0 & 8.0 \\
Methyl linolenate $\left(\mathrm{C}_{19} \mathrm{H}_{32} \mathrm{O}_{2}\right)$ & - & \\
\hline
\end{tabular}

Table 2 Methods of evaluation for all the thermo-physical properties including critical properties

\begin{tabular}{lll}
\hline Thermo-physical property & Method of evaluation & Reference \\
\hline Boiling point & Based on experimental measurement & - \\
Latent heat of vaporisation & Pitzer acentric factor correlation & {$[16]$} \\
Liquid density & Modified Rackett equation & {$[16]$} \\
Liquid heat capacity & Van Bommel correlation & {$[18]$} \\
Liquid surface tension & Correlation proposed by Allen et al. & {$[19]$} \\
\hline
\end{tabular}


Liquid thermal conductivity

Liquid viscosity

Second virial coefficient

Vapour diffusivity

Vapour heat capacity

Vapour pressure

Vapour thermal conductivity

Vapour viscosity

\section{Critical properties}

Critical temperature

Critical pressure

Critical volume
Robbin and Kingsrea method

Orrick and Erbar method, Letsou and Stiel [16] method

Tsonopoulos method

Lennard-Jones potential, Wilke and Lee [16,20] method

Rihani and Doraiswamy method

Modified Antoine equation

Correlation by Chung et al.

Correlation by Chung et al.

Joback modification of Lydersen's method

Joback modification of Lydersen's method [16]

Joback modification of Lydersen's method [16]

\subsection{Experimental setup}

The simulations of non-reacting and reacting sprays for SME were modelled based on the experiment carried out by Nerva et al. [6]. The spray experiment for SME, which utilised the Spray A experimental configurations from Sandia National Laboratory, was operated at an ambient temperature of $900 \mathrm{~K}$ and a ambient density of $22.8 \mathrm{~kg} / \mathrm{m}^{3}$. Fuel was injected by a common rail injector with a total injected mass of $22.7 \mathrm{mg}$ over a duration of $7.5 \mathrm{~ms}$. Further operating conditions of the experimental setup are reported in Nerva et al.'s paper [6]. 

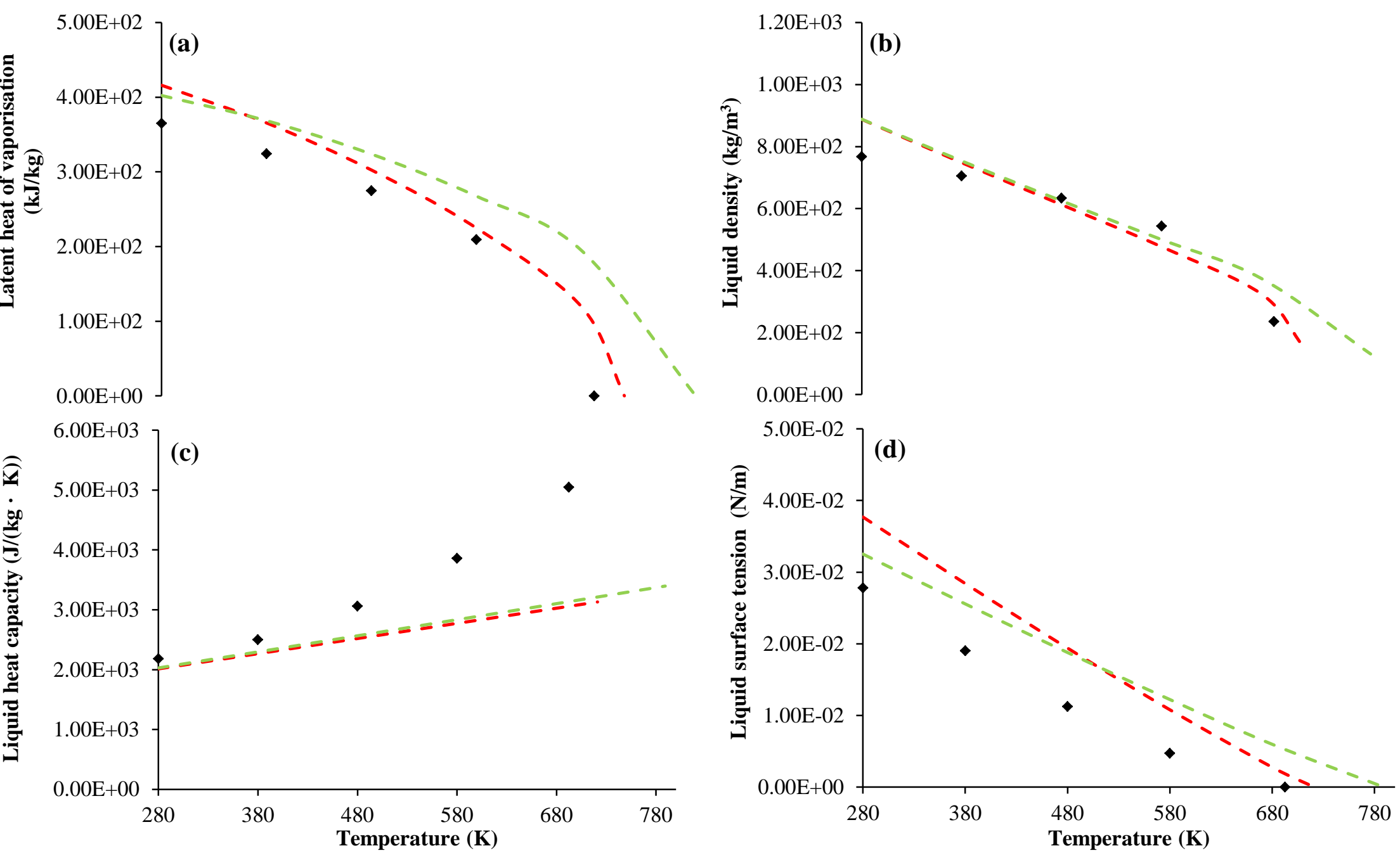

Fig. 1. Evaluated thermo-physical properties of CME, SME and diesel (labelled as $\mathrm{C}_{14} \mathrm{H}_{30}$ ) over temperatures of $280 \mathrm{~K}$ to critical

temperatures of each fuel: (a) latent heat of vaporisation, (b) liquid density, (c) liquid heat capacity, (d) liquid surface tension. 
156

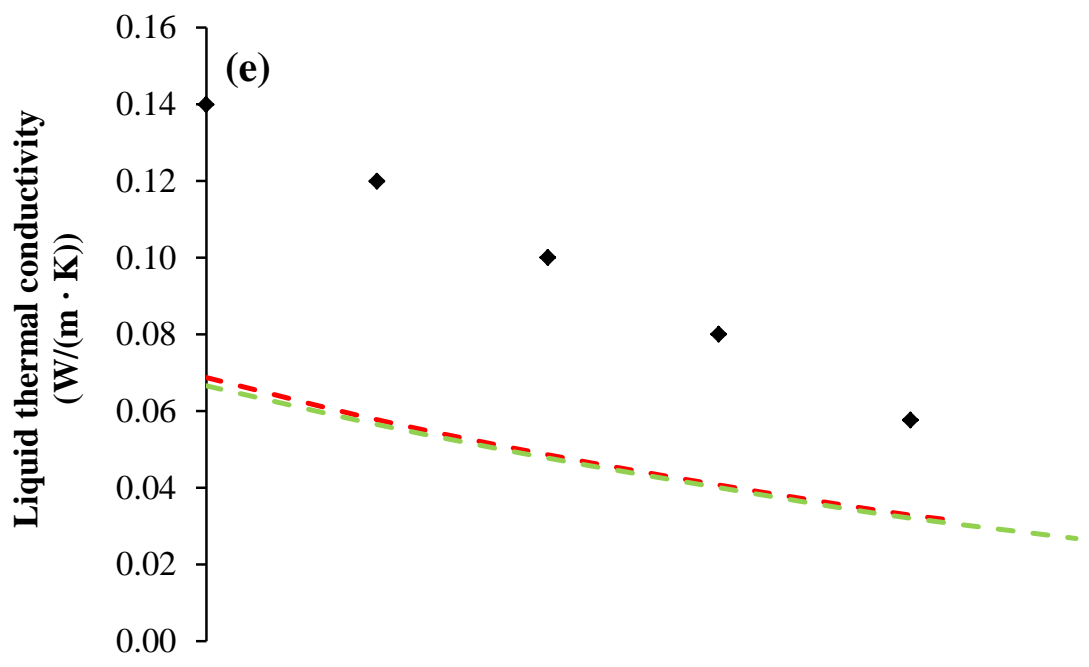

157

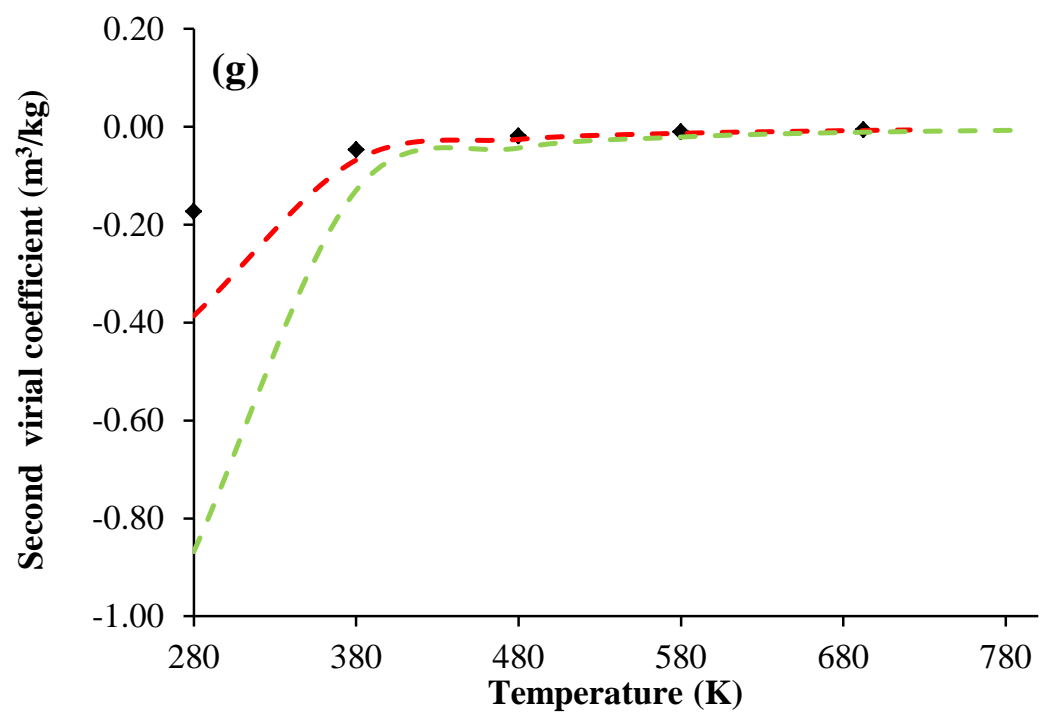

- $\mathrm{C} 14 \mathrm{H} 30$ diffusivity.
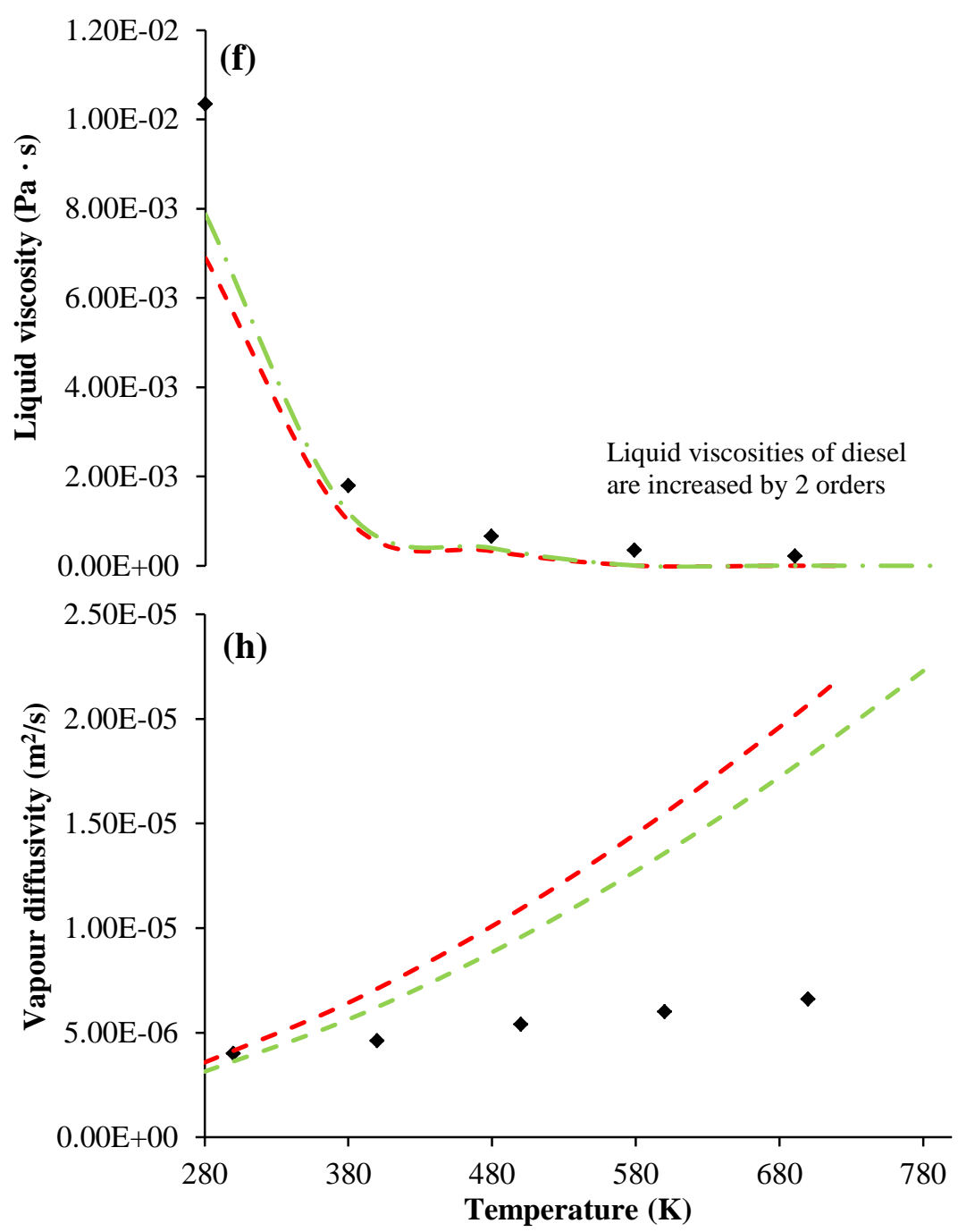

Fig. 1(continued). Evaluated thermo-physical properties of CME, SME and diesel (labelled as $\mathrm{C}_{14} \mathrm{H}_{30}$ ) over temperatures of $280 \mathrm{~K}$ to critical temperatures of each fuel: (e) liquid thermal conductivity, (f) liquid viscosity, (g) second virial coefficient and (h) vapour 

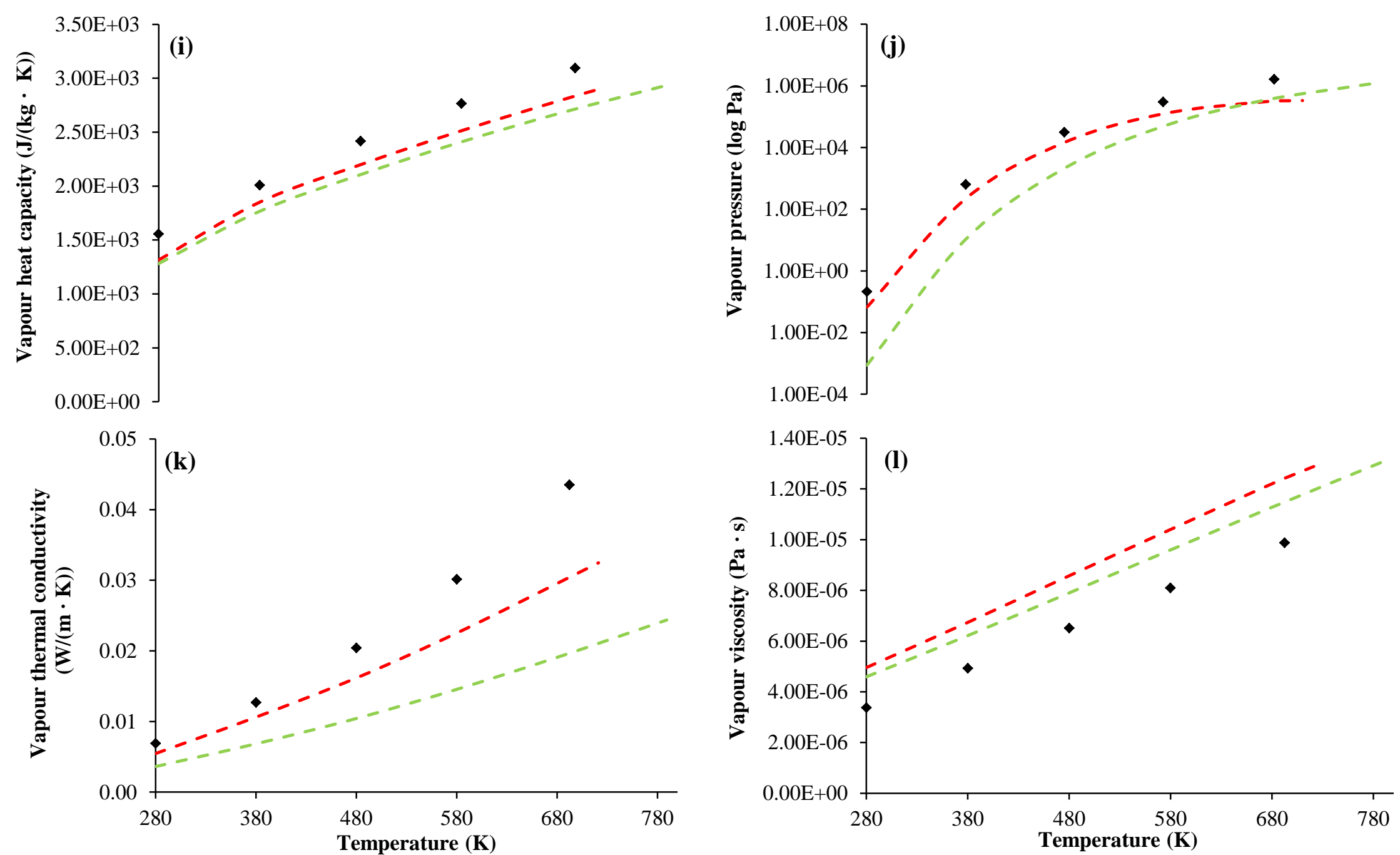

Fig. 1(continued). Evaluated thermo-physical properties of CME, SME and diesel (labelled as $\mathrm{C}_{14} \mathrm{H}_{30}$ ) over temperatures of $280 \mathrm{~K}$ to 


\subsection{Numerical settings}

Numerical simulations of the non-reacting and reacting sprays were performed using

a two-dimensional axi-symmetric wedge mesh, as shown in Figure 2. The computational mesh is a $4^{\circ}$ sector of a cylindrical mesh with a radial length of $54.0 \mathrm{~mm}$ and an axial length adjusted to $138.0 \mathrm{~mm}$ to reproduce the volume of the experiment combustion chamber. For the spatial resolution, cell sizes of $0.25 \mathrm{~mm}, 0.50 \mathrm{~mm}$ and $1.00 \mathrm{~mm}$ were examined in each axial and radial direction, as seen in Figure 3(a)(i) to (b)(ii). Mesh independence was achieved when $0.50 \mathrm{~mm}$ and $0.25 \mathrm{~mm}$ were specified for the initial cell sizes in the axial and radial directions, respectively. Thus, a mesh with 10,816 computational cells was created. resolution. The fixed time-step size of $0.50 \mu$ s as shown in Figure 4(a) and (b), which was found to give mesh independent results, was chosen for the simulations. Table 3 compiles the numerical settings, ambient conditions and boundary conditions defined for the simulations.

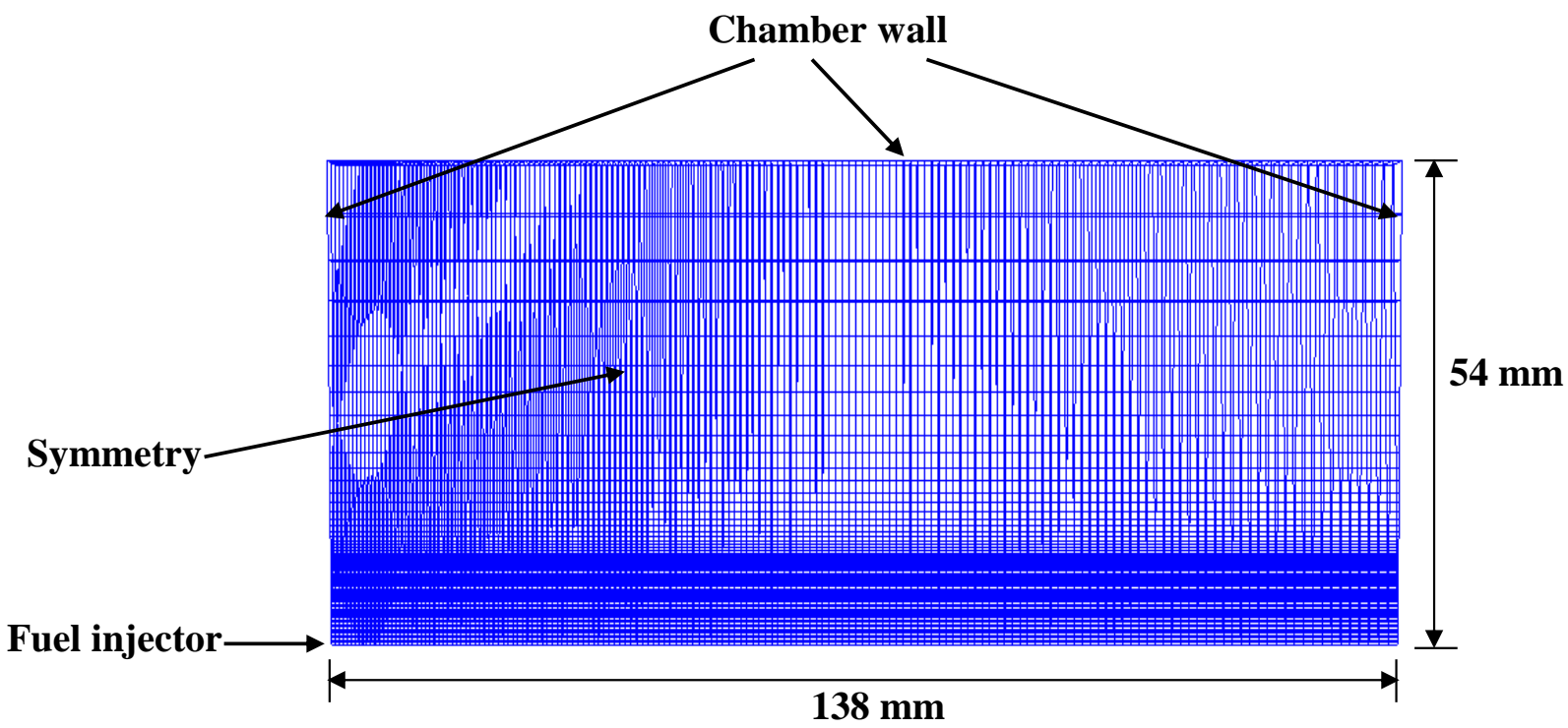



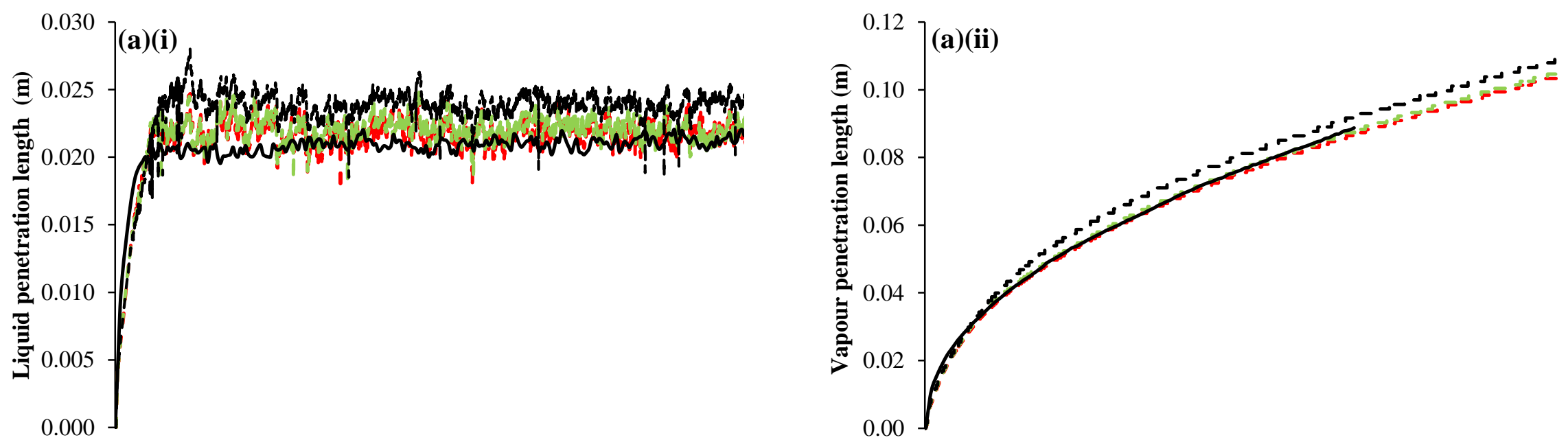

185

$--0.25 \mathrm{~mm} \times 0.25 \mathrm{~mm}---0.50 \mathrm{~mm} \times 0.25 \mathrm{~mm}$
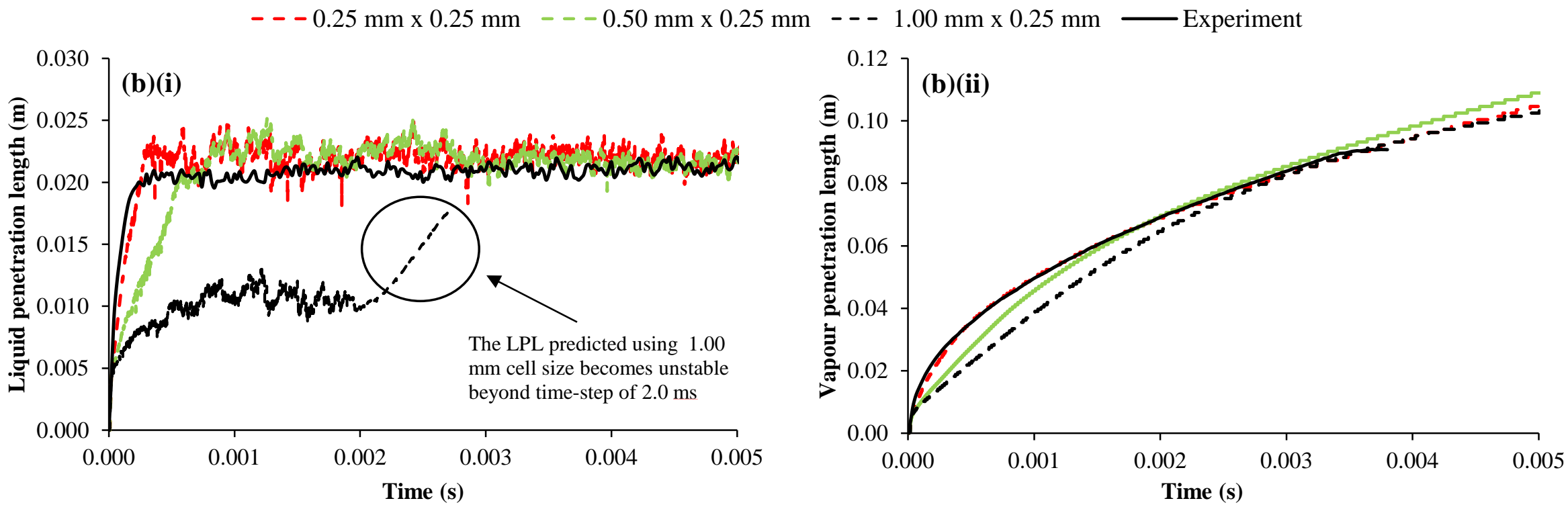

Experiment 


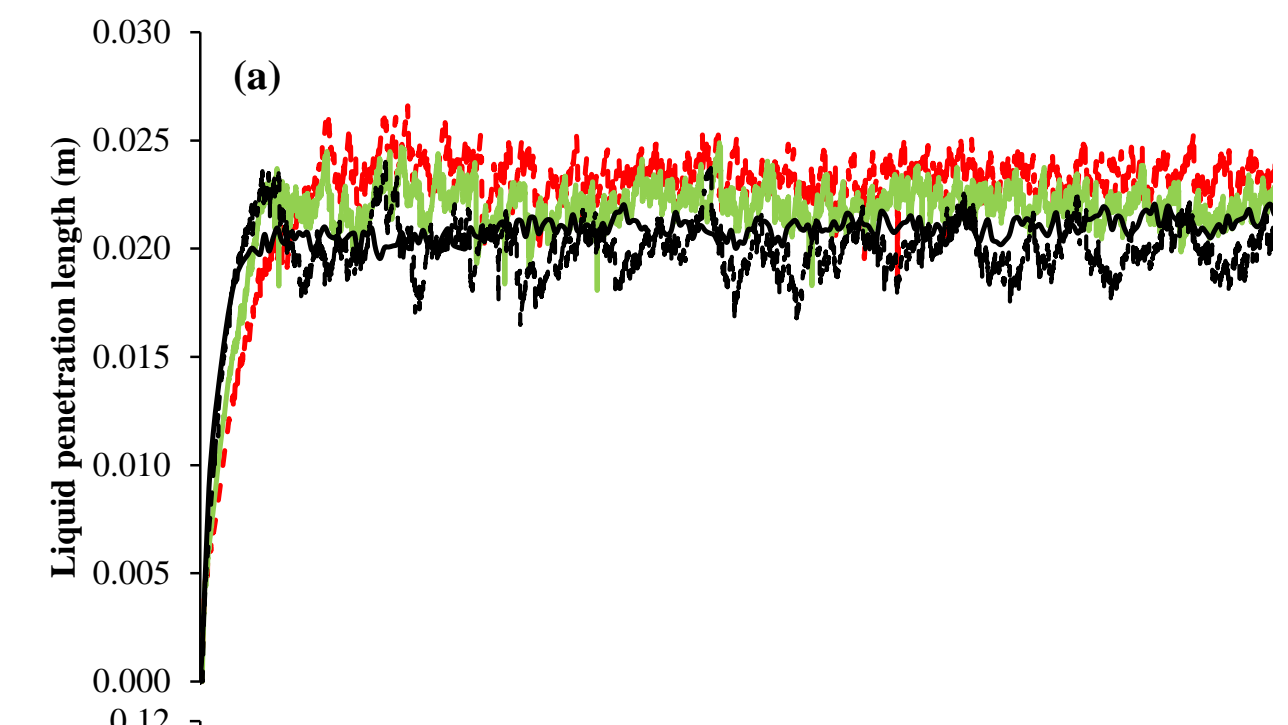

190

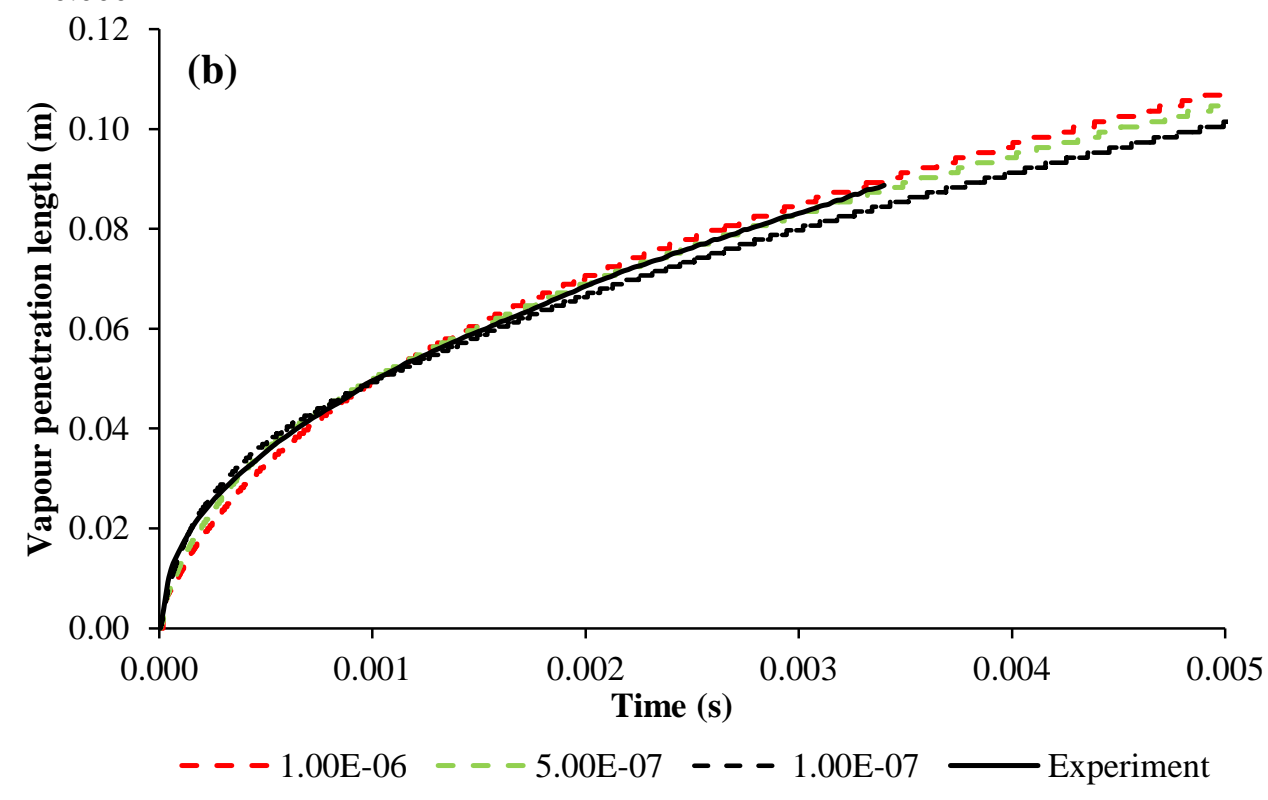

191

192

193

194

195

Fig. 4. Predictions of (a) LPL and (b) VPL against experimental measurements using time-step sizes of $1.0 \mu \mathrm{s}, 0.5 \mu \mathrm{s}$ and $0.1 \mu \mathrm{s}$, at initial temperature of $900 \mathrm{~K}$, non-reacting spray condition.

Here, the spray and turbulence model constants were optimised based on the validations of predicted LPL and VPL predictions against to those of the experiment. The Reitz-Diwakar spray model [22] was selected to estimate the secondary spray breakup of liquid fuel, where two breakup regimes of bag and stripping were modelled. As illustrated in Figure 5, the breakup time constant for stripping, $C_{s}$ was adjusted to 15.0 in order to replicate the measured LPL as compared to 10.0. For the turbulence calculations, three turbulence 
models, namely the standard $k-\varepsilon$, Renormalisation Group (RNG) $k-\varepsilon$ and realizable $k-\varepsilon$ turbulence models, with default turbulence model constant, $C_{\varepsilon l}$ were evaluated. Among these turbulence models, only the LPL and VPL predicted by the standard $k-\varepsilon$ model were the most stable when validated to the experimental measurements as shown in Figure 6(a) and (b), which are identical to the results obtained by Pang et al. [23]. This was because of the fully developed flow generated within the combustion chamber due to a high injection pressure of 1500 bar and an initial velocity of $569.5 \mathrm{~m} / \mathrm{s}$, for which is in line with Ahsan's findings [24]. Therefore, the standard $k-\varepsilon$ model with $C_{\varepsilon l}$ adjusted to 1.58 , which is a similar approach to that of Cheng et al. [25], was selected for the simulations of non-reacting and reacting sprays. The initial values of turbulence kinetic energy, $k$ and dissipation rate, $\varepsilon$ were set to 0.735 $\mathrm{m}^{2} / \mathrm{s}^{2}$ and $3.835 \mathrm{~m}^{2} / \mathrm{s}^{3}$, respectively. Meanwhile, near-wall treatment was excluded in the simulations because it was out of the experimental optical view and not of interest for the current work.

Table 3 Numerical settings, ambient conditions and boundary conditions defined for the simulation of non-reacting and reacting sprays

\begin{tabular}{ll}
\hline Numerical settings & \\
\hline Injector & Solid cone injector \\
Breakup & Reitz-Diwakar \\
Breakup time constant for & 15.0 \\
stripping, $C_{s}$ & \\
Droplet drag & Dynamic \\
Evaporation & Frossling \\
Heat transfer & Ranz Marshall \\
Wall & Reflect \\
Turbulence & Standard $k-\varepsilon$ \\
Turbulence constant, $C \varepsilon_{1}$ & 1.58 \\
Initial grid size in axial direction & 0.50 \\
(mm) & \\
Initial grid size in radial direction & 0.25 \\
\hline
\end{tabular}


$(\mathrm{mm})$

Time step $(\mu \mathrm{s}) \quad 0.50$

Time discretisation PISO

Number of parcels $\quad 70,000$

Soot Leung and Lindstedt

Fuel mechanism MD

MD9D

n-heptane

\begin{tabular}{lll}
\hline Ambient conditions & & \\
\hline Parameter & Initial value & Wall boundary condition \\
Temperature $(\mathrm{K})$ & 900 & Zero gradient \\
Pressure (bar) & 60.0 & Zero gradient \\
Velocity (m/s) & $(0,0,0)$ & Fixed value \\
$k\left(\mathrm{~m}^{2} / \mathrm{s}^{2}\right)$ & 0.735 & Zero gradient \\
$\varepsilon\left(\mathrm{m}^{2} / \mathrm{s}^{3}\right)$ & 3.835 & Logarithmic law-of-the-wall \\
\hline Mole fractions of air composition & & \\
\hline Components & Non-reacting & Reacting \\
$\mathrm{N}_{2}$ & 0.8971 & 0.7515 \\
$\mathrm{O}_{2}$ & 0 & 0.15 \\
$\mathrm{H}_{2} \mathrm{O}$ & 0.0377 & 0.0362 \\
$\mathrm{CO}_{2}$ & 0.0652 & 0.0623 \\
\hline
\end{tabular}

217

For the reacting spray, identical case settings to those of the non-reacting spray were defined. Additionally, an in-house reduced biodiesel mechanism containing surrogate components of methyl decanoate $\left(\mathrm{MD}, \mathrm{C}_{11} \mathrm{H}_{22} \mathrm{O}_{2}\right.$ ), methyl-9-decenoate (MD9D, $\mathrm{C}_{11} \mathrm{H}_{20} \mathrm{O}_{2}$ ) and n-heptane $\left(\mathrm{C}_{7} \mathrm{H}_{16}\right)$ [25] was integrated into the simulations. Although several experiments

222 [26-28] indirectly demonstrate that the selection of chemical kinetics which is based on the fuel surrogate components is influential to the numerical results produced, the chemical kinetics is inevitably adopted to reduce computational complexity and time. Here, the reduced mechanism was selected to match the saturation and unsaturation levels of CME and SME as explained by the Cheng et al. [25], such that the ID, combustion and emissions were 227 predicted according to the change of unsaturation levels. In order to account for the turbulence-chemistry interactions, the well-stirred reactor model was applied to the reacting spray simulations. Meanwhile, the soot library [29], which was developed based on the 
230 Leung and Lindstedt soot model [30], was implemented to model soot formation. Here, 231 acetylene $\left(\mathrm{C}_{2} \mathrm{H}_{2}\right)$ was set as the soot precursor and also the surface growth species. Processes

232 of nucleation, coagulation, surface growth and oxidation due to oxygen $\left(\mathrm{O}_{2}\right)$ and hydroxyl $233(\mathrm{OH})$ radicals were included in the calculation of soot formation. Additional numerical 234 settings are tabulated in Table 3.

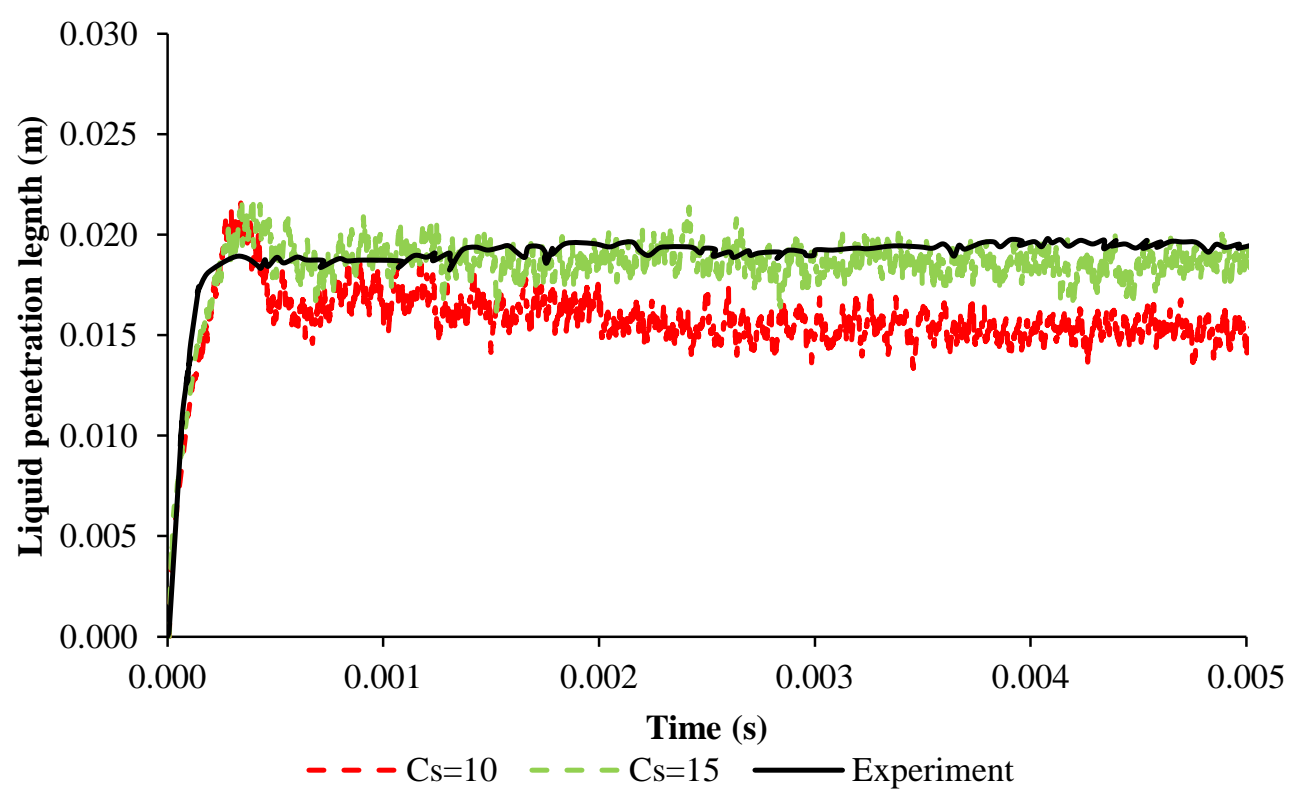

236 Fig. 5. Predictions of LPL against experimental measurement with $C_{s}$ adjusted to 10 and 15, at initial temperature of $900 \mathrm{~K}$, non-reacting spray condition. 

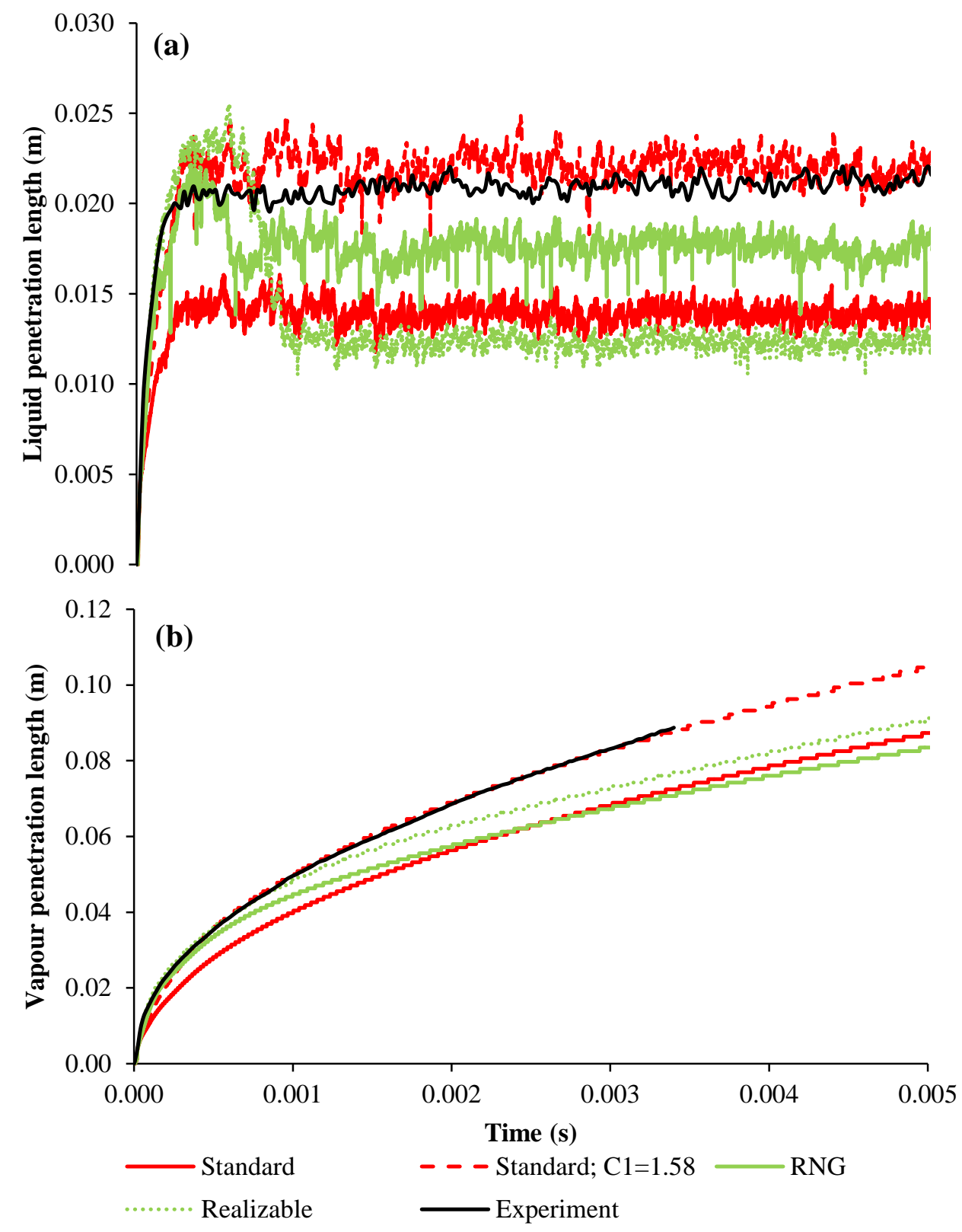

Fig. 6. Predictions of (a) LPL and (b) VPL against experimental measurement using the standard $k-\varepsilon$, RNG $k-\varepsilon$ and realizable $k-\varepsilon$ turbulence models, at initial temperature of $900 \mathrm{~K}$, non-reacting spray condition. integration of all 12 thermo-physical properties was defined as the baseline case. Then, the 
thermo-physical properties of SME were individually replaced by those of the diesel fuel. The significance of the fuel properties was determined based on the deviations found in the predicted spray parameters in comparisons to those of the baseline case. The approach taken here to perform the sensitivity analyses is similar to those carried out by Ra et al. [13] and Mohamed Ismail et al. [14]. Since the experimental data was only available for SME, the simulations for CME were carried out based on the quantitative case settings of SME, except for the thermo-physical properties and fuel compositions.

\subsection{Non-reacting spray}

\subsubsection{Individual thermo-physical property}

This sensitivity analysis was performed to determine the significance of individual thermo-physical property under non-reacting spray condition. The reason for this was to isolate the combustion chemistries effects, such that the fuel spray development was only influenced by the thermo-physical properties. Here, the deviations found in the predictions of LPL, VPL, SMD, radial mixture fraction and fuel evaporation ratio were used to determine the significance of the individual thermo-physical property. These parameters were chosen because these are the key indicators for the spray development. For example, LPL and SMD represent the breakup of liquid fuel, while the mixture fraction and fuel evaporation ratio denote the fuel mixing and evaporation, respectively. Here, LPL was defined as the furthest axial position with $99.0 \%$ of the injected mass entrained. On the other hand, VPL was defined as the distance where $0.1 \%$ of fuel mass was detected. For the predicted LPLs and VPLs, additional relative percentage differences (RPDs) for the individual CME and SME thermophysical property were calculated using Equations (1) and (2). Meanwhile, the radial mixture fraction was obtained at a position $40.0 \mathrm{~mm}$ away from the injector. The fuel evaporation 
ratio as expressed in Equation (3) was defined as the ratio of mass of fuel evaporated to mass of fuel injected [31].

275 Fuel evaporation ratio $=\frac{\text { mass of fuel evaporated }}{\text { mass of fuel injected }}$ increment in the LPLs of SME and CME, with a maximum RPD of 34.6\% among other fuel properties. This is followed by vapour pressure (-17.6\%), liquid heat capacity (7.9\%), liquid density $(-7.0 \%)$ and liquid surface tension $(-4.6 \%)$. Meanwhile, the effects of the remaining fuel properties which include liquid viscosity, vapour heat capacity, second virial coefficient, liquid thermal conductivity, vapour thermal conductivity, vapour viscosity and vapour diffusivity are marginal because the calculated RPDs of these properties are equivalent to that of the baseline case. Whilst, the predicted VPLs for the individual fuel property of SME and CME as illustrated in Figures 7(b) and 8(b) exceed by a maximum RPD of $2.5 \%$, when compared to that of baseline case. One possible reason for this is because the penetration of fuel vapour is mainly governed by the fuel-air mixing and turbulence effects. 

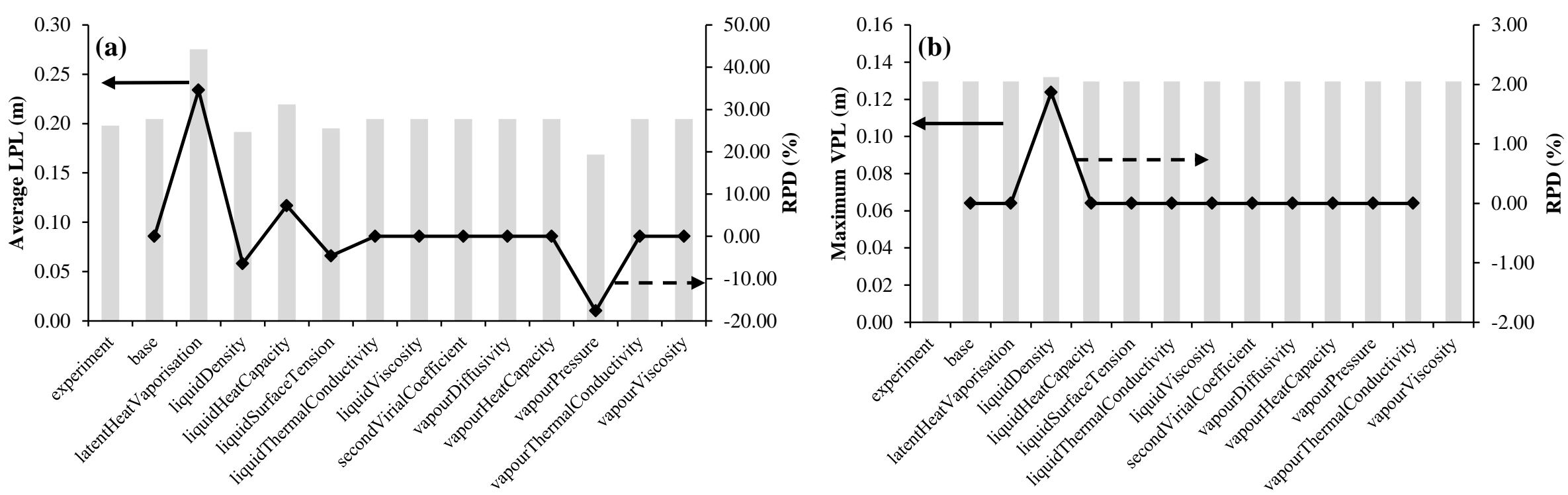

Non-reacting $\rightarrow$ Non-reacting
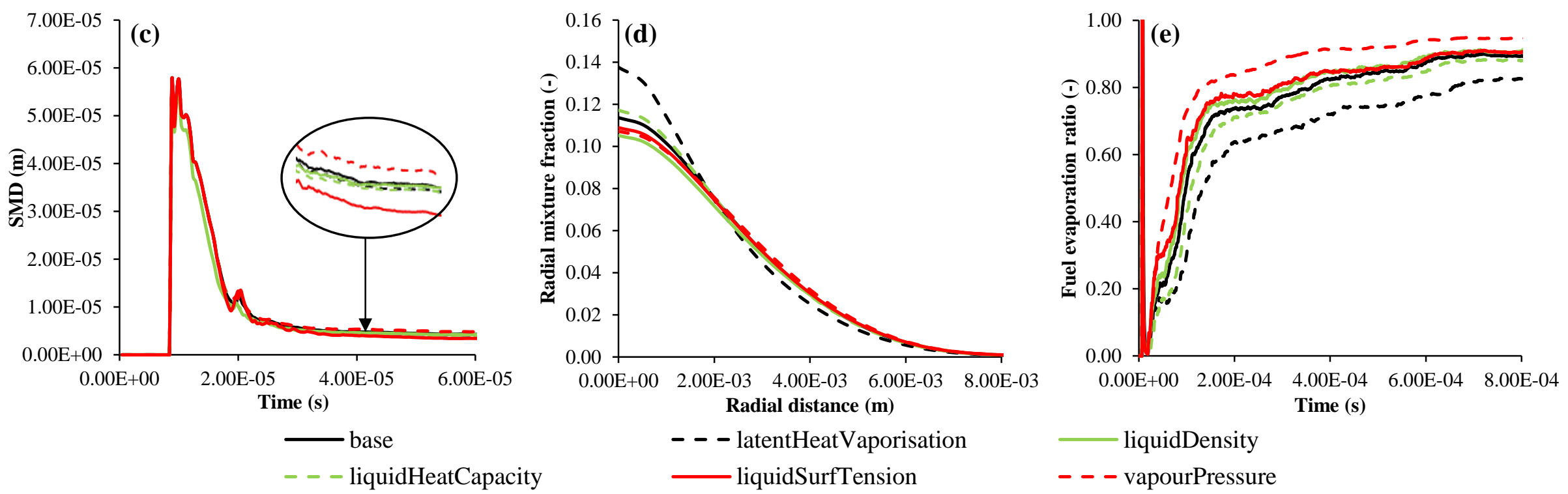

Fig. 7. Sensitivities of individual thermo-physical property of SME under non-reacting spray condition on the predicted (a) LPL (with calculated RPD, plotted as line), VPL (with calculated RPD, plotted as line), (c) SMD, (d) radial mixture fraction and (e) fuel evaporation ratio. 
294

295
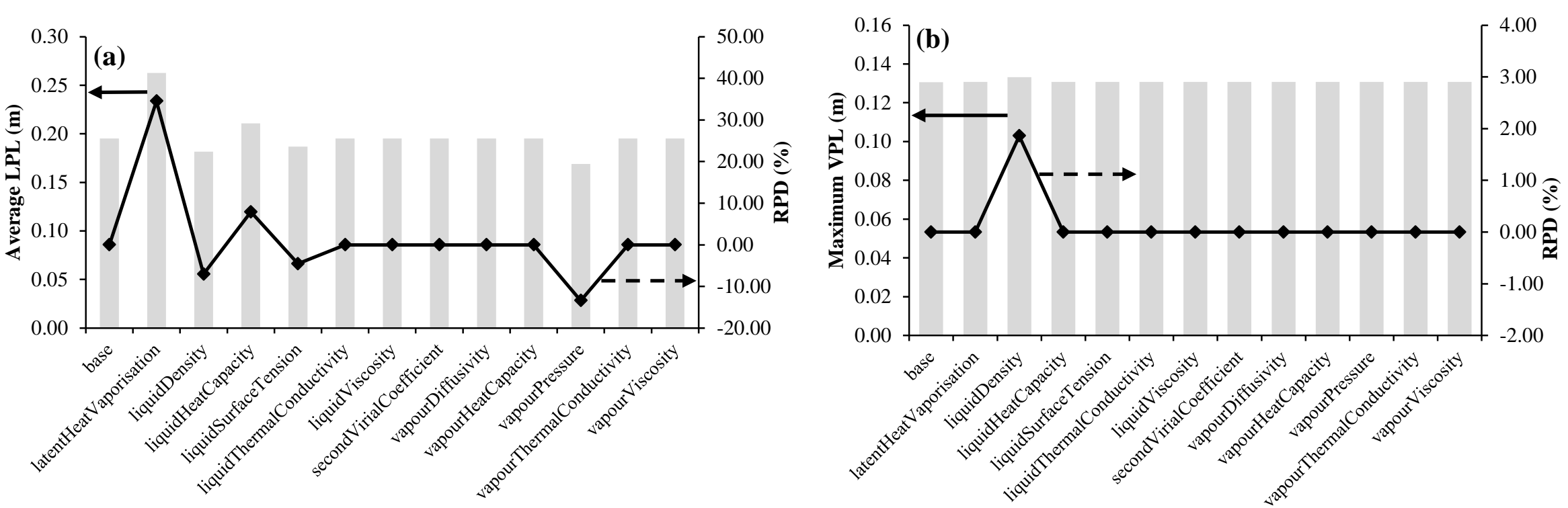

Non-reacting $\rightarrow$ Non-reacting
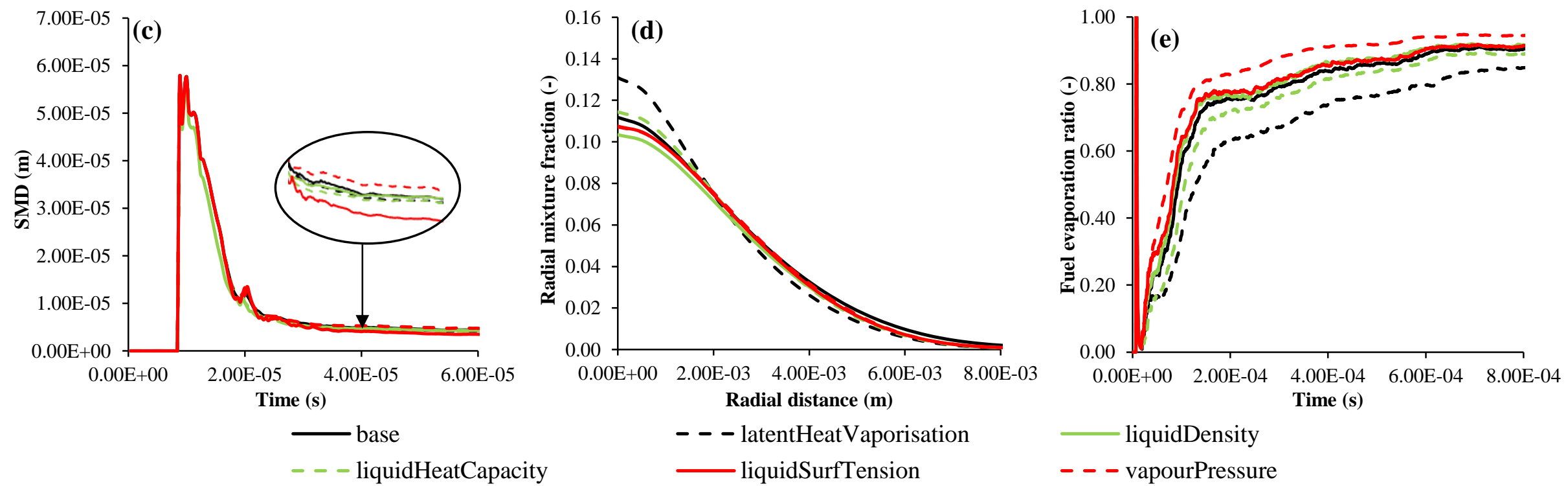

Fig. 8. Sensitivities of individual thermo-physical property of CME under non-reacting spray condition on the predicted (a) LPL (with calculated RPD, plotted as line), (b) VPL (with calculated RPD, plotted as line), (c) SMD, (d) radial mixture fraction and (e) fuel evaporation ratio. 

individual thermo-physical property is only prominent upon reaching steady-state with the exception of liquid density, where the SMDs are generally under-predicted as compared to that of baseline case. However, over-predicted SMD is found for vapour pressure, while the SMD for liquid heat capacity remains unchanged. Here, only the SMDs for vapour pressure and latent heat of vaporisation do not correspond to their LPLs. This in turn shows that the SMD prediction does not necessarily affect the subsequent process of fuel spray penetration. For the predicted mixture fractions, the effect of individual fuel property is equivalent to that of LPL, where latent heat of vaporisations for CME and SME record the highest mixture fraction values of 0.14 and 0.13 than the remaining fuel properties do, as displayed in Figures 7(d) and 8(d). In terms of the calculated fuel evaporation ratios shown in Figures 7(e) and 8(e), latent heat of vaporisation and vapour pressure are clearly the most sensitive fuel properties, for which both properties give the highest and lowest deviations, respectively.

\subsubsection{Coupled thermo-physical properties}

In order to examine the coupled effects of thermo-physical properties on spray development, the significant individual thermo-physical property identified from Section 3.1.1 were iteratively combined together. Based on the average LPL predictions shown in Figure 9(a), coupled effects among the combined individual fuel properties are found for both CME and SME. For example, the coupling of vapour pressure and latent heat of vaporisation (labelled as 2,3 in Figure 9(a)) with average LPL values of $16.9 \mathrm{~mm}$ and $27.5 \mathrm{~mm}$, respectively gives rise to an average LPL of $21.3 \mathrm{~mm}$. The resulting LPL, which is approximately $4.1 \%$ above that of the SME baseline case, indicates that there exists a coupled effect between the two thermo-physical properties. Here, several of the coupled thermo- 
325 physical properties correspond to the relationships found for actual fuel. For example, the 326 couplings between liquid density and liquid surface tension and also liquid density and 327 vapour pressure. Since similar results are obtained in the remaining analyses of CME and 328 SME, the development of fuel spray is thus deduced to be dependent on the coupled effects 329 among the thermo-physical properties.

For the vapour spray development, the coupled effects among the thermo-physical 331 properties are also found as seen in Figure 9(b). Although this demonstrates the dependency 332 of vapour spray development on the thermo-physical properties, the changes observed in 333 VPL are considered insignificant, where the maximum RPD is calculated to be only at $2.5 \%$. 334 These marginal deviations again prove that the development of fuel vapour is also dependent 335 on the physical processes of mixing and turbulence. Since the coupled effects among the 336 thermo-physical properties are co-produced from the individual effects, only the sensitivity of 337 the individual thermo-physical property is further examined in the reacting spray. 


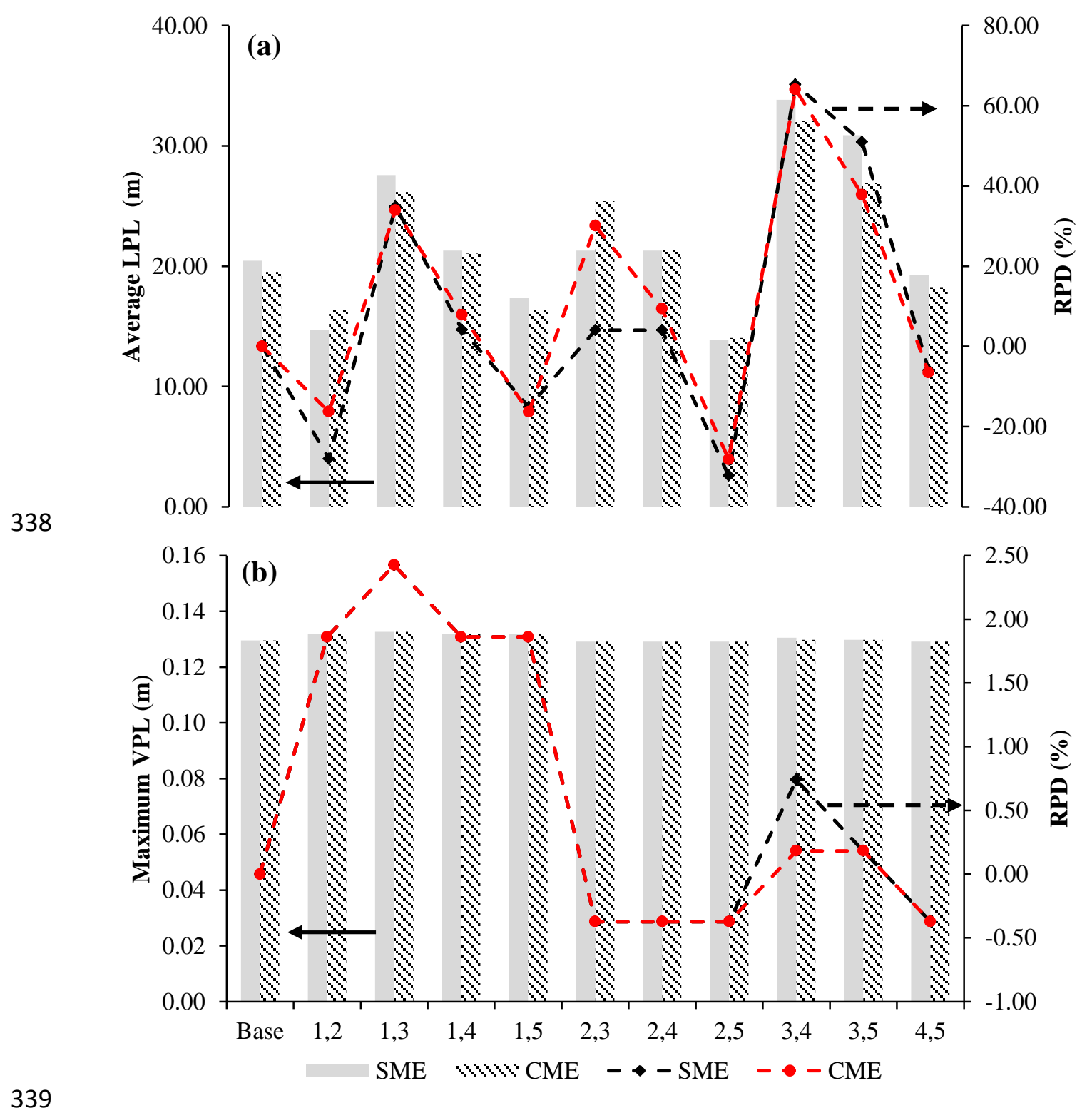

340 Fig. 9. Sensitivities of coupled thermo-physical properties of CME and SME under non341 reacting spray condition on the predicted (a) LPL (with calculated RPD, plotted as line) 342 and (b) VPL (with calculated RPD, plotted as line). Order of the individual thermo343 physical property on the x-axis: 1. Liquid density, 2. Vapour pressure, 3. Latent heat of 344 vaporisation, 4. Liquid heat capacity, 5. Liquid surface tension. 
In this sensitivity analysis, the effect of individual thermo-physical property on spray development was studied for reacting spray, where the combustion chemistries were incorporated. This analysis was performed to further justify the significance of individual thermo-physical property since the development of reacting spray also depends on the combustion chemistries. Here, the case settings and compositions of combustion chemistries for CME and SME were retained during the substitution of thermo-physical properties such that the effects of CFD models and chemical kinetics were maintained throughout the analyses. This was because it was reported that the selection of spray model was found to give impact on the accuracy of numerical results [32]. For example, the fuel composition of SME was fixed at $20.0 \%$ MD and $80.0 \%$ MD9D when the thermo-physical property of SME was individually substituted by that of the diesel fuel.

Additional benchmarking parameters such as ID period, LOL and SVF were included. Here, VPL was excluded since marginal effects of the fuel properties on VPLs as reported in Section 3.1.1 were found. This exclusion was further justified by the observation from Kuti et al.'s work [33], where shorter LPL than flame LOL denoted faster completion of fuel vaporisation before combustion. In this study, the $18.50 \mathrm{~mm}$ LPL predicted for SME is $29.33 \%$ shorter than the LOL of $26.18 \mathrm{~mm}$. Here, ID period was defined as the interval required to reach the largest rate change of temperature $\left(\mathrm{dT} / \mathrm{dt}_{\max }\right)$. Since $\mathrm{OH}$ chemiluminescence was used to measure LOL in the experiment [6], LOL here was determined as the axial distance

367 from the nozzle to the first position where $2.0 \%$ of maximum Favre-averaged $\mathrm{OH}$ radical mass fraction was detected. 


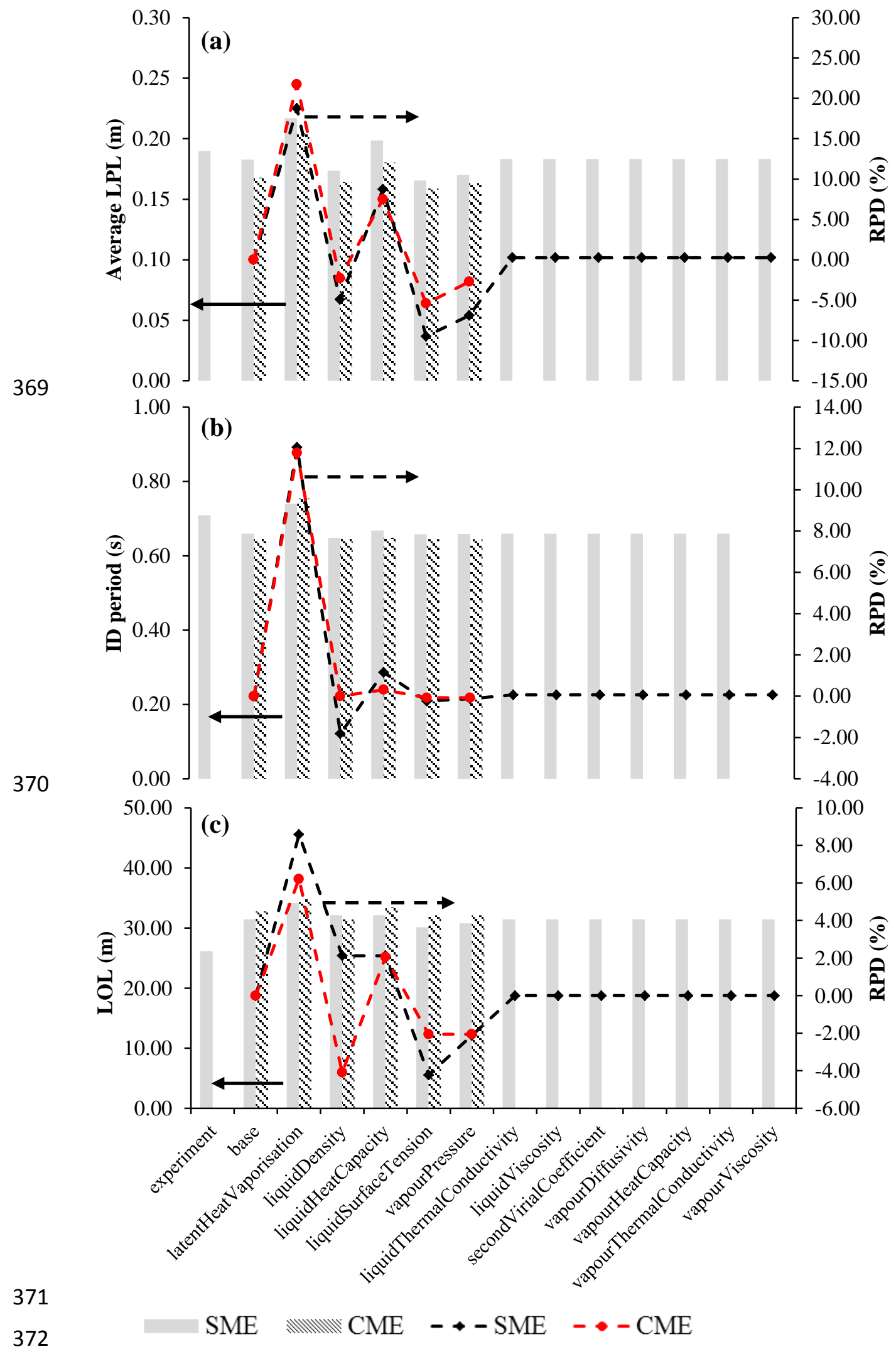

373 Fig. 10. Sensitivities of individual thermo-physical property of SME and CME under

374 reacting spray condition on the predicted (a) average LPL, (b) ID period and (c) LOL.

375 The calculated RPDs are plotted as line. 
377 liquid heat capacity, liquid surface tension, latent heat of vaporisation and vapour pressure are found to be influential, where a maximum RPD of $18.8 \%$ is obtained. On the contrary, the LPLs predicted by liquid viscosity, liquid thermal conductivity, vapour thermal conductivity, vapour diffusivity, vapour viscosity and second virial coefficient were equivalent to those of the baseline case. Since the sensitivities of thermo-physical properties for SME found here are identical to those obtained from the non-reacting spray sensitivity analysis, the remaining sensitivity analyses for CME were only performed for the significant fuel properties.

\section{Results and discussion}

Based on the simulation results estimated from the non-reacting and reacting sprays as illustrated in Figures 7, 8, 10 and 11, the significant thermo-physical properties identified for CME and SME are latent heat of vaporisation, liquid density, liquid heat capacity, liquid surface tension and vapour pressure. These results predicted for CME and SME generate several key observations. According to the calculated RPD shown in Figures 7(a), 8(a) and 10(a), the effects exerted by the individual thermo-physical property (excluding liquid surface tension) on the reacting spray are relatively less than those of the non-reacting spray. These predictions thus prove that the combustion chemistries are involved in the development of reacting spray. Besides, the effects of individual thermo-physical property are also varied in accordance to the unsaturation levels. In the analyses of non-reacting and reacting sprays, the LPL, ID period and LOL predictions for liquid density, liquid heat capacity, liquid surface tension and vapour pressure are extended with the increase of unsaturation levels. On the contrary, reduced RPDs are obtained for latent heat of vaporisation when the unsaturation level increases. Apart from that, the effects of all the thermo-physical properties are also 
varied according to the unsaturation levels. For instance, the predicted ID period of $0.646 \mathrm{~ms}$

401

402

403

404

405

406

407

408

409

410

411

412

413

414

415

416

417

418

419

420

421

422

423

424 for CME, which contains the lowest unsaturation level is approximately $2.2 \%$ shorter than the $0.660 \mathrm{~ms}$ of SME, which has the highest level of unsaturation. Similarly, the predicted SVF is also affected by the unsaturation levels, where CME records a peak SVF of $4.0 \mathrm{ppm}$, while the highest SVF of SME is predicted at $6.0 \mathrm{ppm}$. However, an opposite trend is observed in the LOL, where LOL is shortened with the increase of unsaturation level.

Based on the tested operating conditions and optimised numerical case settings, latent heat of vaporisation and vapour pressure exert the largest influence on the spray development, among the significant thermo-physical properties. In general, spray development is retarded when latent heat of vaporisation is substituted, while the substitution of vapour pressure induces advancement. Comparing the effects of latent heat of vaporisations between CME and SME, the retardation in the spray development produced by the latent heat of vaporisation of CME is less than that of the SME. This is because the evaluated values of latent heat of vaporisation for CME are closer to those of the diesel fuel than SME does, particularly at temperatures above $480 \mathrm{~K}$ as seen in Figure 1(a). For CME and SME, the LPLs predicted in non-reacting and reacting sprays are extended by maximum deviations of $34.6 \%$ and $21.8 \%$, respectively when compared to those of the baseline cases. Despite the $5.0 \%$ decreased in the SMDs predicted for latent heat of vaporisation as shown in Figures 7(c) and 8(c), the longer LPLs for latent heat of vaporisation are supported by the higher value of mixture fraction, as evident in Figures 7(d) and 8(d). Additionally, the lower fuel evaporation ratios shown in Figures 7(e) and 8(e) also suggest longer LPLs as this parameter denotes longer time is needed for the evaporated fuel mass to be equivalent to the injected fuel mass [31]. These results in turn imply that poor mixing is produced with changes in the latent heat of vaporisation. Apart from this, latent heat of vaporisation also demonstrates the largest retardation effects on the ID periods and LOLs, with maximum RPDs of $12.1 \%$ and $8.6 \%$, 
respectively, as shown in Figure 10(b) and (c). Figure 11(a) and (b) illustrates the normalised

426 SVFs along the axial direction, where the width of the SVF profile represents the area of soot

427 formation. Based on Figure 11(a) and (b), the normalised SVF peaks for the latent heat of 428 vaporisations of SME and CME are reduced by RPD of $22.8 \%$ and $15.8 \%$, respectively. Here, 429 the reduced SVF peak predicted for latent heat of vaporisation is caused by the extended LOL, 430 where longer LOL leads to a less fuel rich central reaction zone by allowing more air 431 entrainment [34].

432
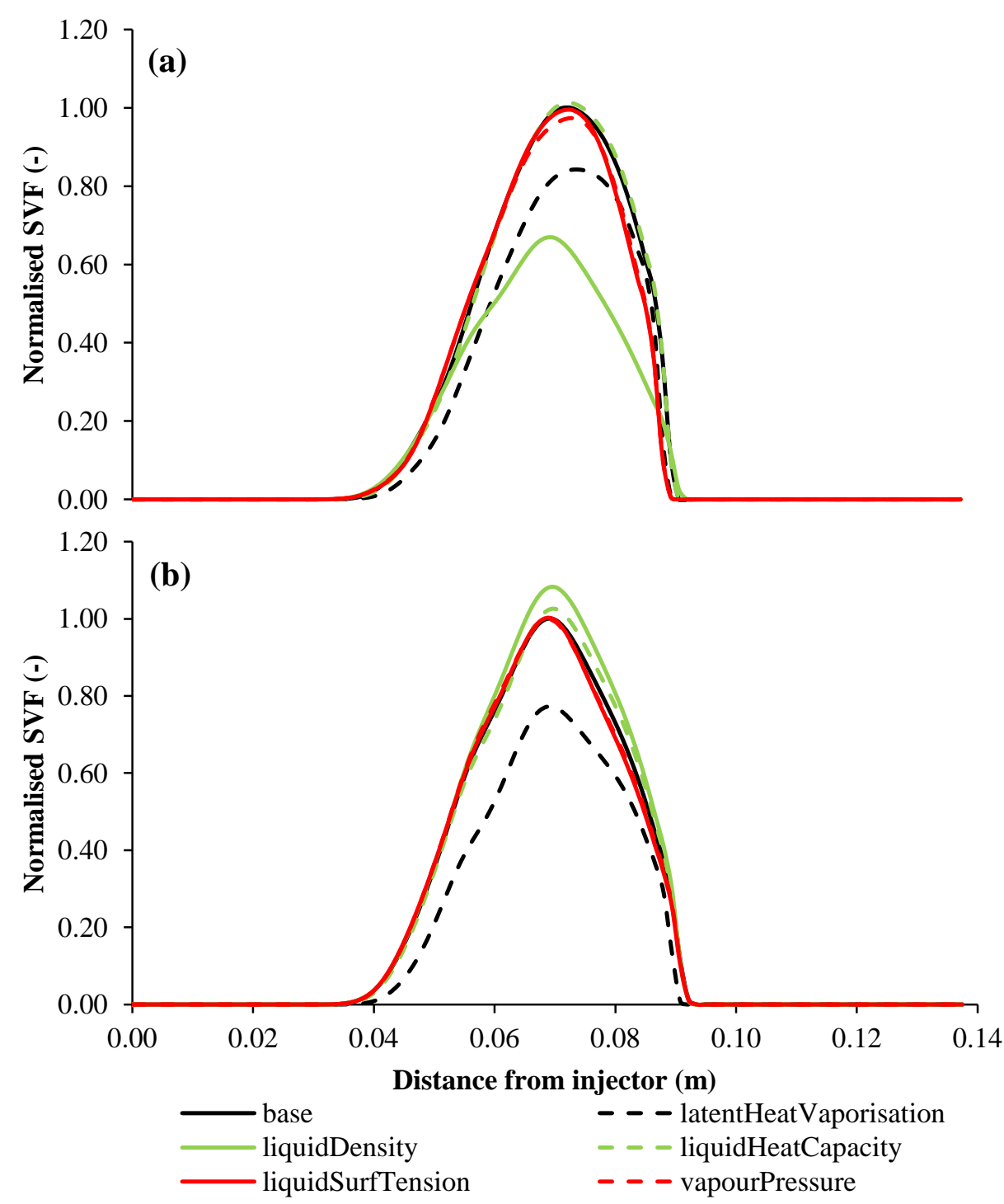
437 Moreover, vapour pressure also denotes the evaporation rate of a fuel [37] since it relates to the tendency of particles to escape from liquid to gaseous phase. For these reasons, reduced LPLs of $17.6 \%$ and $6.9 \%$ are obtained in the non-reacting and reacting sprays, respectively, as seen in Figures 7(a) and 8(a). Here, it is observed that the effects of vapour pressure on the spray development of CME and SME are similar, where a reduced deviation is obtained for both fuels. For both the fuels, the higher rates of fuel evaporation are evident from the lower mixture fractions and higher fuel evaporation ratios as seen in Figures 7(d), (e) and 8(d), (e), although the SMD predictions are about $10.0 \%$ higher than those of the baseline cases. This is because the volatility among the fuel droplets is raised when the lower vapour pressures of CME and SME are replaced by the higher vapour pressures of diesel fuel. As such, the predicted ID periods and LOLs are shortened by $0.1 \%$ and $2.1 \%$, respectively as seen in Figure 10(b) and (c). In terms of the SVF predictions as shown in Figure 11(a) and (b), the normalised SVF peaks for the vapour pressures of CME and SME remain unchanged when compared to those of the baseline cases. This could be attributed to the marginal $0.1 \%$ advanced ID periods and also $2.1 \%$ shortened LOLs, which are insufficient to produce any changes to the soot formed from the nucleation and surface growth processes. Meanwhile, greater deviation in the spray prediction is found as the unsaturation level is increased from CME to SME. Based on Figure 1(j), the evaluated vapour pressures for SME are about 1 order less than those of the CME. These values indicate that higher volatility than CME is expected for SME, when the vapour pressures are replaced by those of the diesel fuel. Therefore, larger RPDs are obtained when the vapour pressures of SME are replaced, as compared to those of the CME. 

7(a) and 8(a), the effect of liquid viscosity is relatively marginal as compared to that of the liquid surface tension. The average value of diesel liquid viscosities at $26.7 \mu \mathrm{Pa}$, which is approximately 2 orders of magnitude lower than those of the CME and SME, is particularly small. Thus, substitution of this fuel property does not produce any effect to the spray development. On the contrary, the impact of liquid surface tension on the spray development is more prominent, where the LPLs and SMDs are under-predicted by $7.1 \%$ and $20.5 \%$, respectively, as seen in Figures 7(a), (c) and 8(a), (c). Comparing the predicted results between CME and SME, it is clear that the influence of liquid surface tension rises as the unsaturation level is increased. This is because the predicted values of liquid surface tension for CME are closer to those of the diesel fuel than the liquid surface tensions of SME are, at temperatures beyond $480 \mathrm{~K}$. The lower values of liquid surface tension from diesel thus allow less tension on the droplet surfaces, and hence fuel droplets are easily atomised. For this reason, the fuel evaporation is improved as illustrated in Figures 7(d), (e) and 8(d), (e). In terms of the ID periods and LOLs, the substitution of liquid surface tension reduces the predictions by $0.2 \%$ and $4.2 \%$, respectively as compared to those of the baseline case. However, these predictions cannot influence the soot development, where the normalised SVF peaks and soot distributions predicted for liquid surface tension are identical to those of the baseline case as displayed in Figure 11(a) and (b).

The replacement of biodiesel liquid heat capacities to those of the diesel fuel gives rise to an increased LPL prediction when compared to that of the baseline case, as seen in Figures 7(a) and 8(a). This is because the liquid heat capacities of diesel are $29.2 \%$ higher than those of the biodiesel, where larger amount of heat is required to break up the fuel droplets. In addition, the unchanged SMDs as shown in Figures 7(c) and 8(c) further restrict the atomisation and breakup processes to transform fuel droplets into gaseous particles. This is also evident with the lower fuel evaporation ratio and higher mixture fraction as compared 
to those of the baseline case, as seen in Figures 7(d), (e) and 8(d) and (e). Since the liquid

487

488

489

490

491

492

493

494

495

496

497

498

499

500

501

502

503

504

505

506

507

508

509

510 heat capacities predicted for CME and SME are almost identical as seen in Figure 1(c), the substitution of this fuel property to that of the diesel fuel therefore induces identical RPDs in the predictions of LPL, ID period and LOL for both fuels. Here, the ID periods and LOLs for both fuels are extended with maximum RPD of $1.2 \%$ and $2.1 \%$, respectively. Furthermore, the subsequent soot formation is also affected, where marginal increments in the normalised SVF peaks of $3.0 \%$ and $1.0 \%$ are observed for CME and SME, respectively as illustrated in Figure 11(a) and (b).

Figure 1(b) displays the evaluated liquid densities for diesel and biodiesel, where the liquid densities of diesel are $37.0 \%$ lower than those of CME and SME. When the liquid densities of biodiesel are substituted by those of diesel, fuel droplets with smaller SMD are produced, particularly before $0.02 \mathrm{~ms}$ as seen in Figures $7(\mathrm{c})$ and $8(\mathrm{c})$. The decrease in SMD leads to higher surface to volume ratio and thus the penetration of liquid fuel is lowered. The subsequent fuel evaporation is promoted because of the smaller fuel droplets produced, as evident in Figures 7(d), (e) and 8(d), (e). In the reacting spray analysis, the predicted ID period and LOL with the substitution of liquid density are subjected to an increase of $1.8 \%$ and $2.1 \%$ for SME, as displayed in Figure 10(b) and (c). For CME, the ID period remains identical to that of the baseline case, while the LOL is in contrast to that of SME as a shortened length of $31.5 \mathrm{~mm}$ is obtained. Here, the SVF distributions predicted for the liquid densities of CME and SME are entirely different. The liquid density of CME displays an 8.0\% increase in the normalised SVF peak, as well as an expanded soot area when compared to those of the baseline case, as seen in Figure 11(b). On the contrary, lower normalised SVF peak of $33.1 \%$ and reduced soot area are obtained when comparing the prediction for SME liquid density to that of the baseline case, as seen in Figure 11(a). These results evidently prove that liquid density is sensitive to the saturation and unsaturation levels. 

conductivity, vapour viscosity, vapour thermal conductivity, vapour diffusivity, vapour heat capacity and second virial coefficient, the predicted LPLs in non-reacting and reacting sprays are identical to those of their respective baseline cases, as seen in Figures 7(a), 8(a) and 10(a). Similarly, the effects of these fuel properties are also marginal based on the predictions of the ID period and LOL as illustrated in Figure 10(b) and (c), where a maximum deviation of only $0.06 \%$ is recorded for the ID periods, whilst the LOLs are identical to that of the baseline case. These results suggest that the vapour thermo-physical properties are insignificant to the spray development. This is because the vapour properties take place after the fuel droplets are vaporised to gaseous particles through the processes of spray breakup and mixing.

\section{Conclusions}

523 Based on the sensitivity analyses performed for non-reacting and reacting sprays, five significant thermo-physical properties are identified. These properties include latent heat of vaporisation, liquid density, liquid heat capacity, liquid surface tension and vapour pressure. Among the identified thermo-physical properties for both CME and SME, latent heat of vaporisation gives the largest deviations of $35.0 \%$ in LPL, $12.1 \%$ in ID period and $8.6 \%$ in LOL. The poor mixing predicted for latent heat of vaporisation as indicated by the higher mixture fraction contributes to a $22.8 \%$ decreased SVF peak as compared to that of baseline case. Meanwhile, liquid density demonstrates two contrasting effects on the soot concentration. The SVF peak predicted for SME is reduced by $33.1 \%$, while the SVF peak

532 for CME is raised by $8.0 \%$. This proves that the effects of thermo-physical properties vary according to unsaturation levels. Despite the varied LPLs, ID periods and LOLs predicted for vapour pressure, liquid heat capacity, liquid surface tension and liquid density, these 
535 variations are insufficient to affect the SVF. In the reacting spray analyses, the individual 536 thermo-physical property exhibits identical effects as compared to those of non-reacting 537 spray, although at reduced level of magnitudes. Apart from that, coupled effects among the 538 thermo-physical properties are also discovered, where the effects are combined from the 539 effects of individual thermo-physical property. These results, which are computed for the 540 selected operating conditions and numerical models, thus show that the individual and 541 coupled effects of the thermo-physical properties are important to the development of the fuel 542 spray and soot processes. 


\section{Nomenclature}

\begin{tabular}{|l|l|}
\hline Abbreviation & Computational fluid dynamics \\
\hline CFD & Acetylene \\
\hline $\mathrm{C}_{2} \mathrm{H}_{2}$ & Cyclohexane \\
\hline $\mathrm{C}_{6} \mathrm{H}_{12}$ & n-heptane \\
\hline $\mathrm{C}_{7} \mathrm{H}_{16}$ & n-tetradecane \\
\hline $\mathrm{C}_{14} \mathrm{H}_{30}$ & Heneicosane \\
\hline $\mathrm{C}_{21} \mathrm{H}_{44}$ & Coconut methyl ester \\
\hline CME & Fatty acid methyl ester \\
\hline FAME & Ignition delay \\
\hline ID & Lift-off length \\
\hline LOL & Liquid penetration length \\
\hline LPL & Methyl decanoate \\
\hline MD & Methyl-9-decenoate \\
\hline MD9D & Oxygen \\
\hline $\mathrm{O}_{2}$ & Hydroxyl \\
\hline OH & Open Field Operation and Manipulation \\
\hline OpenFOAM & Palm methyl ester \\
\hline PME & Renormalisation group \\
\hline RNG & Relative percentage difference \\
\hline RPD & Sauter mean diameter \\
\hline SMD & Soybean methyl ester \\
\hline SME & Soot volume fraction \\
\hline SVF- & Vapour penetration length \\
\hline VPL & Turbulence model constant (-) \\
\hline Symbols & Breakup time constant for stripping $(-)$ \\
\hline$C_{\varepsilon 1}$ & Turbulence dissipation rate ( $\left.{ }^{2} / \mathrm{s}^{3}\right)$ \\
\hline$C_{s}$ & Turbulence kinetic energy ( $\left.{ }^{2} / \mathrm{s}^{2}\right)$ \\
\hline$E$ & \\
\hline$K$ & \\
\hline & \\
\hline &
\end{tabular}




\section{Acknowledgements}

The Ministry of Higher Education (MOE) Malaysia is gratefully acknowledged for the financial support towards this project under the Fundamental Research Grant Scheme (FRGS) F0014.54.02. The authors also wish to thank Dr. L. M. Pickett and Dr. J.-G. Nerva for providing additional (processed) data for model validation. 


\section{References}

[1] Xue J, Grift TE, Hansen AC. Effect of biodiesel on engine performances and emissions. Renew Sustain Energy Rev 2011;15:1098-116.

[2] Rounce P, Tsolakis A, York APE. Speciation of particulate matter and hydrocarbon emissions from biodiesel combustion and its reduction by aftertreatment. Fuel 2012;96:90-9.

[3] Jung H, Kittelson DB, Zachariah MR. Characteristics of SME biodiesel-fueled diesel particle emissions and the kinetics of oxidation. Environ Sci Technol 2006;40:4949-55.

[4] Özener O, Yüksek L, Ergenç AT, Özkan M. Effects of soybean biodiesel on a DI diesel engine performance, emission and combustion characteristics. Fuel 2014;115:875-83.

[5] Genzale CL, Pickett LM. Liquid Penetration of Diesel and Biodiesel Sprays at LateCycle Post-Injection Conditions. SAE Int J Engines 2010;3:479-95.

[6] Nerva J-G, Genzale CL, Kook S, Garcia-Oliver JM, Pickett LM. Fundamental spray and combustion measurements of soy methyl-ester biodiesel. Int $\mathbf{J}$ Engine Res 2012;14:373-90.

[7] Kuti OA, Zhu J, Nishida K, Wang X, Huang Z. Characterization of spray and combustion processes of biodiesel fuel injected by diesel engine common rail system. Fuel 2013;104:838-46.

[8] Lee Y, Huh KY. Numerical study on spray and combustion characteristics of diesel and soy-based biodiesel in a CI engine. Fuel 2013;113:537-45.

[9] Yuan W, Hansen AC, Zhang Q. Predicting the physical properties of biodiesel for combustion modeling. ASAE 2003;46:1487-93.

[10] An H, Yang WM, Maghbouli A, Chou SK, Chua KJ. Detailed physical properties prediction of pure methyl esters for biodiesel combustion modeling. Appl Energy 2013;102:647-56.

[11] Anand K, Sharma RP, Mehta PS. A comprehensive approach for estimating thermophysical properties of biodiesel fuels. Appl Therm Eng 2011;31:235-42.

[12] Cheng X, Ng HK, Gan S, Ho JH. Advances in computational fluid dynamics (CFD) modeling of in-cylinder biodiesel combustion. Energy \& Fuels 2013;27:4489-506.

[13] Ra Y, Reitz R, McFarlane J, Daw C. Effects of fuel physical properties on diesel engine combustion using diesel and bio-diesel fuels. SAE Int J Fuels Lubr 2008;1:70318.

[14] Mohamed Ismail H, Ng HK, Cheng X, Gan S, Lucchini T, D'Errico G. Development of thermophysical and transport properties for the CFD simulations of in-cylinder biodiesel spray combustion. Energy \& Fuels 2012;26:4857-70. 
[15] Yuan W, Hansen AC, Zhang Q. Vapor pressure and normal boiling point predictions for pure methyl esters and biodiesel fuels. Fuel 2005;84:943-50.

[16] Reid RC, Prausnitz JM, Sherwood TK. The properties of gases and liquids. $4^{\text {th }}$ ed. New York: New York McGraw-Hill; 1987.

[17] Lin R, Tavlarides LL. Thermophysical properties needed for the development of the supercritical diesel combustion technology: Evaluation of diesel fuel surrogate models. J Supercrit Fluids 2012;71:136-46.

[18] Van Bommel V, Oonk H, Van Miltenberg J. Heat capacity measurements of 13 methyl esters of n-carboxylic acids from methyl octonoate to methyl eicosanoate between $5 \mathrm{~K}$ and 350K. J Chem Eng 2004;49:1036-42.

[19] Allen CAW, Watts KC, Ackman RG. Predicting the surface tension of biodiesel fuels from their fatty acid composition. J Am Oil Chem Soc 1999;76:317-23.

[20] Poling B, Prausnitz JM, O'Connell J. The Properties of Gases and Liquids. $5^{\text {th }}$ edition. New York: New York McGraw-Hill; 2001.

[21] Chung TH, Ajlan M, Lee LL, Starling KE. Generalized multiparameter correlation for nonpolar and polar fluid transport properties. Ind Eng Chem Res 1988;27:671-9.

[22] Reitz RD, Diwakar R. Effect of drop breakup on fuel sprays. SAE Tech Pap 860469; 1986.

[23] Pang KM, Jangi M, Bai X-S, Schramm J. Investigation of chemical kinetics on soot formation event of n-heptane spray combustion. SAE Tech Pap 2014-01-1254; 2014.

[24] Ahsan M. Numerical analysis of friction factor for a fully developed turbulent flow using $\mathrm{k}-\varepsilon$ turbulence model with enhanced wall treatment. Beni-Suef Univ J Basic Appl Sci 2014;3:269-77.

[25] Cheng X, Ng HK, Gan S, Ho JH, Pang KM. Development and validation of a generic reduced chemical kinetic mechanism for CFD spray combustion modelling of biodiesel fuels. Combust Flame 2015;162:2354-70.

[26] Yu X, Luo X, Jansons M, Kim D, Martz J, Violi A. A Fuel Surrogate Validation Approach Using a JP-8 Fueled Optically Accessible Compression Ignition Engine. SAE Int J Fuels Lubr 2015;8:119-34.

[27] Dooley S, Won SH, Chaos M, Heyne J, Ju Y, Dryer FL, Kumar K, Sung C-J, Wang H, Oehlschlaeger MA, Santoro RJ, Litzinger TA. A jet fuel surrogate formulated by real fuel properties. Combust Flame 2010;157:2333-9.

[28] Dooley S, Won SH, Heyne J, Farouk TI, Ju Y, Dryer FL, Kumar K, Hui X, Sung C-J, Wang H, Oehlschlaeger MA, Iyer V, Iyer S, Litzinger TA, Santoro RJ, Malewicki, Brezinsky $\mathrm{K}$. The experimental evaluation of a methodology for surrogate fuel formulation to emulate gas phase combustion kinetic phenomena. Combust Flame 2012;159:1444-66. 
[29] Pang KM, Jangi M, Bai X-S, Schramm J. Evaluation and optimisation of phenomenological multi-step soot model for spray combustion under diesel engine-like operating conditions. Combust Theory Model 2015:1-30.

[30] Leung KM, Lindstedt RP. A simplified reaction mechanism for soot formation in nonpremixed flame. Combust Flame 1991;87:289-305.

[31] Tonini S, Gavaises M, Arcoumanis C. Prediction of liquid and vapor penetration of high pressure diesel sprays. SAE Tech Pap 2006-01-0242; 2006.

[32] Galle J, Verschaeren R, Verhelst S. The behavior of a simplified spray model for different diesel and bio-diesel surrogates. SAE Tech Pap 2015-01-0950; 2015.

[33] Kuti O, Sarathy M, Nishida K, Roberts W. Studies of spray combustion processes of palm oil biodiesel and diesel fuels using reduced chemical kinetic mechanisms. SAE Tech Pap 2014-01-1143; 2014.

[34] Siebers D, Higgins B. Flame lift-off on direct-injection diesel sprays under quiescent conditions. SAE Tech Pap 2001-01-0530; 2001.

[35] Goodrum JW. Volatility and boiling points of biodiesel from vegetable oils and tallow. Biomass and Bioenergy 2002;22:205-11.

[36] Guo Y, Wei H, Yang F, Li D, Fang W, Lin R. Study on volatility and flash point of the pseudo-binary mixtures of sunflowerseed-based biodiesel+ethanol. J Hazard Mater 2009;167:625-9.

[37] Okamoto K, Watanabe N, Hagimoto Y, Miwa K, Ohtani H. Changes in evaporation rate and vapor pressure of gasoline with progress of evaporation. Fire Saf $\mathrm{J}$ 2009;44:756-63.

[38] Lefebvre AH. Gas Turbine Combustion. $2^{\text {nd }}$ edition. Philadelphia: Taylor and Francis; 1998. 